Discussion

Papers

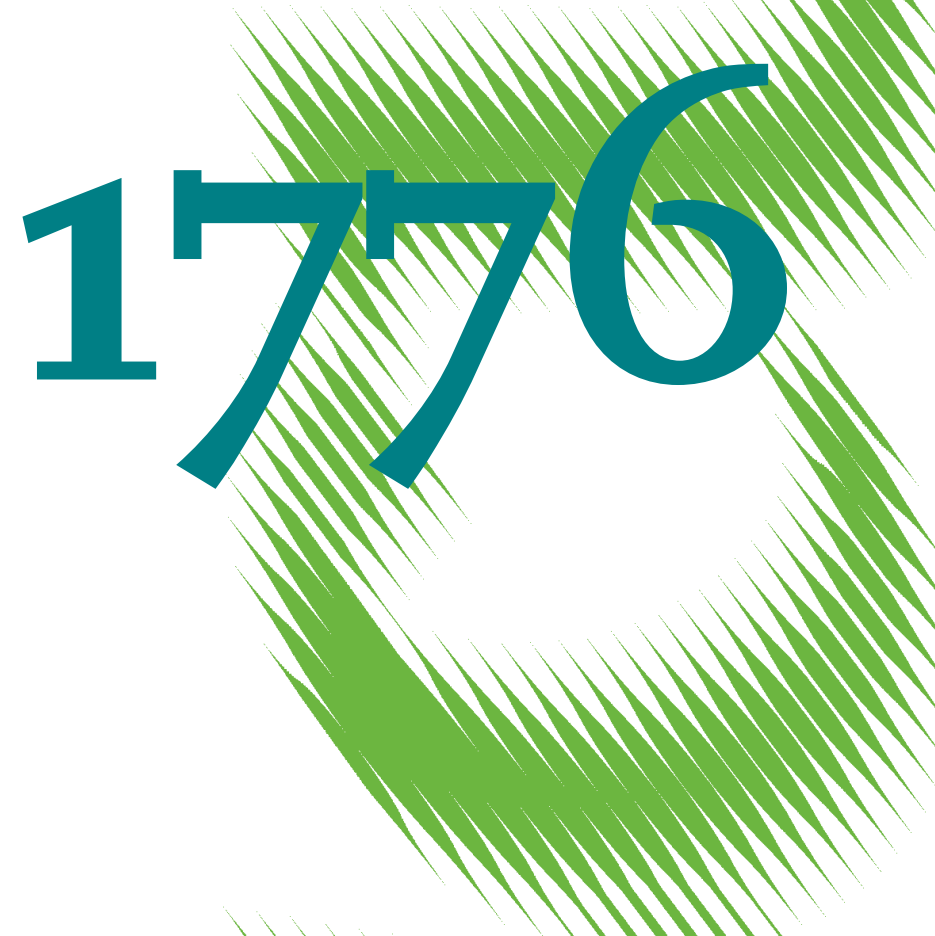

Distributional Impacts of

Climate Mitigation Policies -

a Meta-Analysis 
Opinions expressed in this paper are those of the author(s) and do not necessarily reflect views of the institute.

IMPRESSUM

(C) DIW Berlin, 2018

DIW Berlin

German Institute for Economic Research

Mohrenstr. 58

10117 Berlin

Tel. +49 (30) $89789-0$

Fax +49 (30) $89789-200$

http://www.diw.de

ISSN electronic edition 1619-4535

Papers can be downloaded free of charge from the DIW Berlin website:

http://www.diw.de/discussionpapers

Discussion Papers of DIW Berlin are indexed in RePEc and SSRN:

http://ideas.repec.org/s/diw/diwwpp.html

http://www.ssrn.com/link/DIW-Berlin-German-Inst-Econ-Res.html 


\title{
Distributional Impacts of Climate Mitigation Policies \\ a Meta-Analysis
}

Nils Ohlendorf ${ }^{1, *}$ Michael Jakob ${ }^{1,2,3}$ Jan Christoph Minx ${ }^{1,2,3}$ Carsten Schröder ${ }^{4,5}$ Jan Christoph Steckel ${ }^{1,2,3}$

\footnotetext{
${ }^{1}$ Mercator Research Institute on Global Commons and Climate Change, Torgauer Staße 12-15, 10829 Berlin, Germany

2 Technische Universität Berlin, Department of Economics of Climate Change, Straße des 17. Juni 145, 10623 Berlin, Germany

${ }^{3}$ Potsdam Institute for Climate Impact Research, Telegrafenberg A 31, 14473 Potsdam, Germany

${ }^{4}$ Deutsches Institut für Wirtschaftsforschung, Mohrenstraße 58, 10117 Berlin, Germany

${ }^{5}$ Freie Universität Berlin, Kaiserswerther Straße 16/18, 14195 Berlin, Germany
}

\begin{abstract}
Understanding the distributional impacts of market-based climate policies is crucial to design economically efficient climate change mitigation policies that are socially acceptable and avoid adverse impacts on the poor. Empirical studies that examine the distributional impacts of carbon pricing and fossil fuel subsidy reforms in different countries arrive at ambiguous results. To systematically determine the sources of variation between these outcomes, we apply an ordered probit meta-analysis framework. Based on a comprehensive, systematic and transparent screening of the literature, our sample comprises 53 empirical studies containing 183 effects in 39 countries. Results indicate a significantly increased likelihood of progressive distributional outcomes for studies on lower income countries and transport sector policies. The same applies to study designs that consider indirect effects, behavioral adjustments of consumers or lifetime income proxies. Future research on different types of revenue recycling schemes and lower income countries would further contribute to the literature.
\end{abstract}

Keywords: Meta-analysis, Environmental policies, Distributional impacts, Inequality, Climate change mitigation, Households, Environmental taxes, Redistribution, Poverty

JEL Codes: H23, Q52, Q58 


\section{Introduction}

It is well understood, that in order to achieve international climate targets as agreed in Paris, global greenhouse gas emissions need to decrease rapidly in the upcoming years (IPCC, 2014). In order to achieve this goal, market-based instruments, such as carbon taxes, cap-and trade systems or fossil fuel subsidy reforms, are frequently recommended by leading economists such as Nicolas Stern and Joseph Stiglitz (High-Level Commission on Carbon Prices, 2017). Economic theory highlights that these instruments are environmentally effective and economically efficient (Pigou, 1920; Nordhaus, 1991; Pearce, 1991) ${ }^{1}$. In 2018, 51 carbon pricing schemes, such as carbon taxes or cap-and-trade systems were implemented or planned, covering 20 percent of the global greenhouse gas emissions (World Bank and Ecofys, 2018). Commitment was made to the phase-out of fossil fuel subsidies by the G20 in 2009 at the Pittsburgh summit (G20 Leaders Statement, 2009) and several reforms have been enacted in recent years ${ }^{2}$ (IEA and OECD, 2017).

The distributional impacts of carbon and energy taxes however strongly influence the political acceptability (Baumol and Oates, 1988; Baranzini et al., 2000; Tiezzi, 2005). Regressive distributional impacts harm vulnerable groups and decrease the likelihood of policies being implemented and sustained (Parry, 2015). Social equity concerns can thus quickly dominate the public debate if energy prices increase (Shammin and Bullard, 2009). For example, the incidence and the distributional impacts of the repealed Australian carbon tax were subject to public and academic debate (Rahman, 2013; Sajeewani et al., 2015). The progressive Nigerian fuel and petrol subsidy reform in 2012 even resulted in mass protests and strikes which led to a partial reimplementation (Soile and $\mathrm{Mu}, 2015$; Lockwood, 2015; Dorband et al., 2017) ${ }^{3}$.

\footnotetext{
${ }^{1} \mathrm{~A}$ global carbon tax might however be less efficient when considering a voluntary participation decision by the participating countries (McEvoy and McGinty, 2018). Non-market-based policies might be suitable complements when accounting, e.g. for knowledge spillovers (Fischer and Newell, 2008), technological learning (Kalkuhl et al., 2012) or in the presence of rent seeking (MacKenzie and Ohndorf, 2012).

${ }^{2}$ Only in the first half of 2017, energy subsidy reforms were enacted in Argentina, Bangladesh, Indonesia, Kuwait, Mexico, Mozambique, Pakistan and Zambia (IEA, 2017).

${ }^{3}$ Public protests furthermore led to the reimplementation of subsidies in Venezuela (1989), Yemen (2005), Cameroon (2008) and Bolivia (2010) (Clements et al., 2013).
} 
The literature on the distributional impacts of climate policies provides ambiguous results. Many studies find an overall tendency for regressive impacts (Araar et al., 2011; Gonzalez, 2012). Others detect mostly regressive findings for developed countries while developing countries show an inconsistent picture with a tendency towards proportional or progressive impacts (Verde and Tol, 2009; Wang et al., 2016). Nevertheless, progressive impacts have also been shown for developed countries like Australia (Sajeewani et al., 2015), Canada (Dissou and Siddiqui, 2014) and Spain (Labandeira et al., 2009).

Previous literature reviews provide initial insights but do not systematically explain outcome heterogeneity, i.e. what drives the differences in results of studies. Wang et al. (2016) have conducted the most comprehensive literature review on distributional impacts of carbon prices so far. They consider distributional impacts across households differing by income, location and demographic characteristics. This broad scope provides valuable insights into various dimensions of distributional impacts. However, a common problem ailing most literature reviews is the lack of explicit or transparent selection and evaluation criteria for their study sets as well as rigorous methods for analysis of observed variation which exposes them to the criticism of subjectivity and a lack of validity. The literature on meta-analysis is littered with examples that show how traditional literature reviews and vote counting approaches can be misleading and inconsistent in their assessment of the state-of-art (Stanley and Doucouliagos, 2012; Ringquist, 2013).

We focus our analysis on distributional impacts across household income groups. This narrow scope allows the use of a meta-analysis to quantitatively determine the sources of variation in the study outcomes. A meta-analysis in general is a "systematic, quantitative, replicable process of synthesizing numerous and sometimes conflicting results from a body of original studies" with the potential to provide scientifically robust results (Ringquist, 2013, p. 3). Thus far, meta-analyses have mainly been applied in the fields of education and medicine, but organizations like the Campbell Collaboration or the Collaboration for Environmental Evidence have tried to establish rigorous quality standards and mainstream such work in the social and environmental sciences. In fact, there is an increasing 
volume of meta-analyses in social science including environmental economics (Moeltner et al., 2007; Nelson and Kennedy, 2009; Tunçel and Hammitt, 2014).

This study applies an ordered probit meta-analysis framework to 53 original studies providing 183 effects in 39 countries. We include moderator variables accounting for different policies, modeled economic effects, and countries, while controlling for a publication bias and a time trend. We find a significantly increased likelihood of progressive study outcomes for lower income countries and transport policies. The same applies to study designs considering indirect effects, behavioral adjustments of consumers, or lifetime income proxies. In contrast, we find that subsidy reforms are not inherently more progressive than carbon pricing instruments.

We structure the remainder of this paper as follows: Section 2 elaborates our four key hypotheses with respect to theory and literature findings. Section 3 describes the data selection process, explains the variables and introduces the quantitative model. Section 4 presents the main results while Section 5 discusses and concludes the findings.

\section{Hypotheses}

Literature findings and economic theory indicate the country's level of development, the policy type, the affected sectors and the modeled economic effects to systematically influence the study outcomes. The following paragraphs discuss these factors that might drive the results and subsequently develop hypotheses about the estimated impact.

First, literature reviews show mostly regressive impacts in developed countries. Developing countries, however, show an inconsistent picture with a tendency towards proportional or progressive impacts (Verde and Tol, 2009; Wang et al., 2016). These findings could be explained by low carbon intensities of the consumption baskets of poor households in lower income countries, resulting from a higher share of subsistence consumption, a low access to modern energy services, or the lack of affordability of energy. In fact, Flues and van Dander (2017) demonstrate a negative correlation between the energy affordability risk and GDP, for 20 OECD countries.

Second, literature reviews strongly suggest progressive outcomes for reforms that decrease or abolish fossil fuel subsidies (Anand et al., 2013; Clements et al., 2013; Coady 
et al., 2015) while carbon pricing policies show ambiguous impacts (Wang et al., 2016). Fossil fuel subsidies have primarily been implemented in developing countries (Coady et al., 2015). Currently implemented fossil fuel subsidies are mostly regressive as they especially benefit well-organized interest groups while disadvantaging low-income households that spend relatively little on energy (Inchauste and Victor, 2017). Small groups of powerful and highly profiting actors have a greater incentive to organize and influence a legislative process than a large group of individuals with low payoffs (Oye and Maxwell, 1994). The political economy in combination with the consumption baskets of households in developing countries might thus explain the progressive literature findings for subsidy reforms.

Third, Wang et al. (2016) review a tendency towards progressive outcomes for transport sector policies. Others however show proportional or regressive outcomes in the United States (Casler and Rafiqui, 1993; Chernick and Reschovsky, 1997; Metcalf, 1999; Chernick and Reschovsky, 2000; Williams et al., 2015), Germany (Nikodinoska and Schröder, 2016) and six other European countries (Sterner, 2012). Sterner (2012) argues that the smaller car ownership rate in low-income countries makes fuel a luxury product. Santos and Catchesides (2005) however also find a lower car ownership rate for low-income household in the United Kingdom, resulting in a reverse U-shape relationship between income and incidence. The efficiency of the public transport system as well as indirect fuel expenditures on public transport could additionally influence the results (Datta, 2010). Nevertheless, Kpodar (2006) and Ziramba (2009) find no impact of indirect expenditures.

Finally, we compare the modeling of indirect effects, behavioural adjustments of consumers, general equilibrium effects and studies that apply lifetime income proxies. We thus complement the previous discussion on policy and country impacts by considering different study designs and their corresponding modeled economic effects (see Section 3). Distributional analyses at least consider direct effects, i.e. the price increase of all goods that directly contain $\mathrm{CO}_{2}$, such as gasoline. The following paragraphs discuss the potential impact of additional economic effects on the study outcomes. 
Indirect effects might influence the distributive impact in both directions. Generally, their impact depends on the relative difference of $\mathrm{CO}_{2}$ intensities in the consumption baskets between low- and high-income households (Anand et al., 2013). Hasset et al. (2009) provide evidence that indirect effects mitigate regressivity in the United States. Other authors show that indirect effects increase regressivity as low-income households tend to spend large fractions of their incomes on energy intensive food and public transport (Jacobsen et al., 2003; da Silva Freitas et al., 2016).

Modeling behavioural adjustments of consumers could also ambiguously influence the study outcomes. The impact depends on differences in the demand elasticities between low- and high-income households. Zhang (2015) shows larger behavioural adjustments for richer households and argues that low-income households are required to focus on their basic needs and hence less responsive to price signals. On the contrary, West and Williams (2004) show larger behavioural adjustments for low-income households which results in more progressive outcomes. Their study however only considers transport fuel taxes.

We expect more progressive outcomes for studies that capture general equilibrium effects. Several studies find general equilibrium effects to foster progressive outcomes (Rausch et al., 2011; Dissou and Siddiqui, 2014; Vandyck and Van Regemorter, 2014; Beck et al., 2015; Sajeewani et al., 2015; da Silva Freitas et al., 2016). Dissou and Siddiqui (2014) show that carbon taxes particularly affect the capital-intensive energy industry. This decreases the capital income of rich households and thus makes the distributive effect more progressive. Fullerton and Heutel (2011), however, highlight the results' sensitivity on parameter values.

Using lifetime income proxies, rather than annual household incomes, is hypothesized to increase progressivity. Several literature findings based on lifetime incomes show more progressive outcomes for excise and transport taxes (Poterba, 1989, 1991; Bull et al., 1994; Lyon and Schwab, 1995; Hassett et al., 2009). The permanent income hypothesis (Friedman, 1957) assumes that households smooth their consumption over their lifetime. Accordingly, lifetime income proxies consider that low annual incomes in isolated years 
do not necessarily correspond to low welfare as, for instance, elderly people and students tend to live on savings or loans. The magnitude of the effect (Fullerton and Rogers, 1993), as well as the most suitable lifetime income proxy (Metcalf, 1999; Chernick and Reschovsky, 2000), are widely debated.

Based on this discussion, we hypothesize an increasing share of progressive study outcomes for first, low-income countries, second, subsidy reforms and third, transport sector policies. We also expect more progressive findings for studies that model general equilibrium effects or use lifetime income proxies. Studies that consider indirect and behavioural effects could either provide more progressive or more regressive findings.

\section{Methodology}

We apply a meta-regression framework to analyze literature on the distributional impacts of carbon pricing schemes on households. This section explains how studies were selected and provides an overview of the sample. It also describes the dependent and independent variables and the empirical strategy.

\subsection{Data selection}

We follow Ringquist (2013) for the structure of the data selection process. For literature identification we conduct a query search in the Web of Science and the Scopus literature databases. We connect three groups of keywords with boolean operators filtering for research on $\mathrm{CO}_{2}$ related (carbon, $\mathrm{CO}_{2}$, gasoline, emission, environment, ecologic, energy) pricing policies (tax, allowance, subsidy, policy, price) investigating the distributional impacts (distribution, regressive, progressive, incidence, inequality, household income). We exclude findings from unrelated research fields by permitting characteristic keywords (see Appendix A.1 for details). The literature search identified 1023 studies restricted to literature written in English. In the first step, we exclude 856 studies with titles indicating irrelevant research questions, leaving 167 potentially relevant studies.

For the next steps of the selection process we apply the following study selection criteria ${ }^{4}$. First, we exclude 61 studies because of differing research questions, replicating

\footnotetext{
${ }^{4}$ The numbers of excluded studies per selection criterion in this paragraph already include another 18 excluded studies from an additional reference search (see below).
} 
findings of previous studies including double hits, unavailability or insufficient quality. Second, we only select quantitative studies, thus excluding 34 studies that provide qualitative results or apply theoretical models. Third, we exclude 46 studies with an incomparable scope, i.e. studies pricing multiple pollutants beyond $\mathrm{CO}_{2}$, imposing sectoral restrictions apart from transport, including revenue recycling schemes or only concentrating on urban or rural households. Last, we only select countries or large regions, thus excluding 8 studies for single cities and supranational unions.

Figure 1: Study selection process

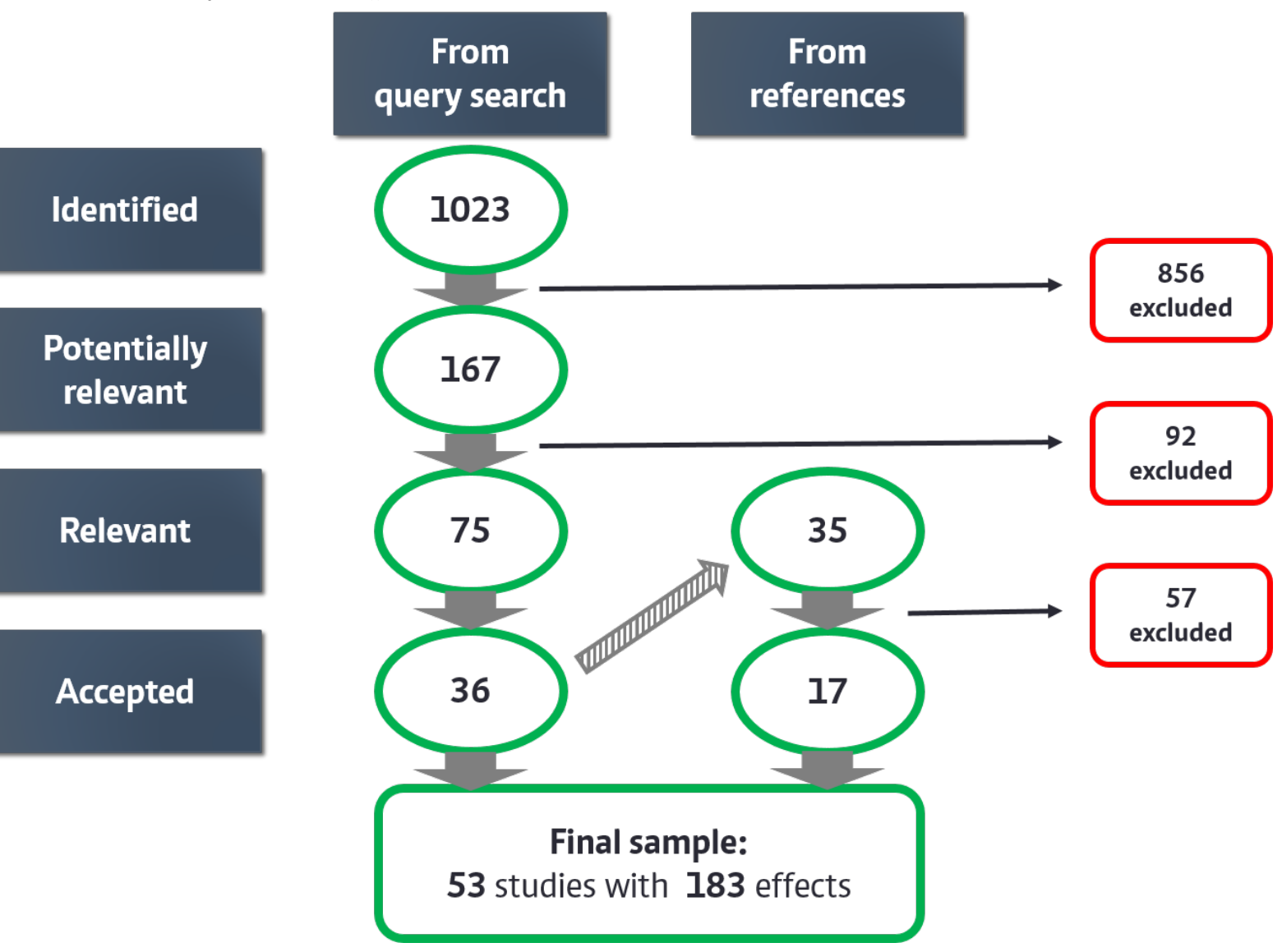

We employ these selection criteria successively to the abstract and the full text of the 167 (potentially) relevant studies, resulting in 36 acceptable studies. In order to supplement our sample by grey literature and literature from other databases we subsequently screen the references of all acceptable studies from the query search to identify further relevant studies. Based on this reference search, we identify another 35 relevant studies, resulting in another 17 acceptable studies. The final sample comprises 53 original studies with 183 effects. Figure 1 provides an overview of the selection process. In total, three 
researchers were involved in the coding process. One researcher coded all 53 studies. Each of the two additional researchers double coded a subsample in the early coding process to identify potential ambiguities in the variable definitions or coding mistakes. Further details are documented in the codebook which is available upon request.

\subsection{Sample overview}

The final sample comprises 53 studies with 183 effects in total. The original study author names, the publication years, the number of included effects per study and the percentage share of included effects per study relative to the 183 total effects are listed in the Appendix A.2. All studies were published between 1991 and 2017 with an average publication year of $2007^{5}$. Most original studies report several effects which account for alternative policies, different model setups or multiple countries. The number of effects per study are thus unequally balanced with Flues and Thomas (2015) providing $22.4 \%$ of the sample, Sterner (2012) 14.2\% and Hasset et. al (2009) 6.6\% while the other studies contribute less than 5\%. The 53 studies include 46 peer-reviewed journal articles (126 effects) and 7 articles from grey literature (57 effects).

Figure 2 shows the number of effects and the percentage share of the total sample for each country included. The effects per country are also unequally balanced, with the United States 30.6\%, the United Kingdom $6.6 \%$ and Germany $4.9 \%$ contributing the largest shares in the sample. Grouping the effects by World Bank country income levels provides 144 effects for high-income countries and 39 effects for low, lower-middle and upper-middle income countries.

\subsection{Dependent variable}

The ordered categorical variable Distributional impact captures the progressive, proportional or regressive distributive impact of each effect included. We only aim to explain whether a policy is progressive, regressive or proportional, without addressing the size of this effect, as the inequality measures applied in the original studies are not quantitatively comparable. The methods suggested by the meta-analysis literature to harmonize

\footnotetext{
${ }^{5}$ The list of potentially relevant studies included publications starting from 1976 . However, no study before 1991 matched our selection criteria.
} 
Figure 2: Country sample overview

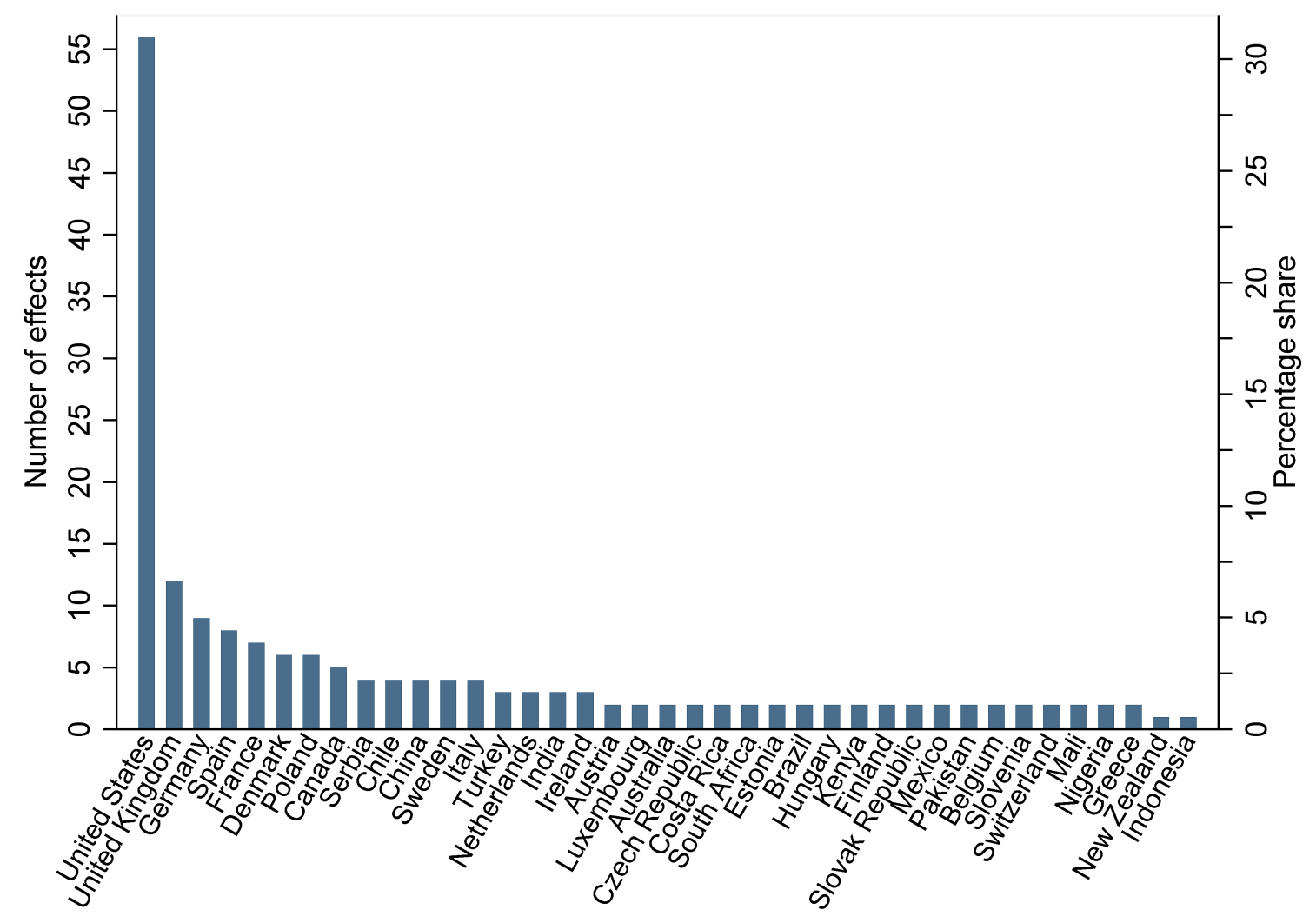

different effect size metrics are not applicable to this study ${ }^{6}$. We also tried to subsample studies with identical inequality metrics, but unfortunately the sample sizes became too small to conduct an empirical analysis. Section 5 discusses the implications of abstracting from the effect size. Neglecting the effect size increases the significance and validity of the results as it allows us to examine a larger sample of original studies. The 183 effects comprise 52 progressive, 13 proportional and 118 regressive outcomes (see Table I).

\subsection{Moderator variables}

Moderator variables are hypothesized to systematically influence the outcomes of the original studies (Ringquist, 2013). We include moderator variables that allow us to test the hypotheses developed in Section 2. The policy and the country moderator variables account for differences in the presumed distributional impact while the economic effect

\footnotetext{
${ }^{6}$ Quantitatively comparing the change of a country's Gini coefficient with a graphical representation of the relative tax burden for each income decile is not feasible. For more details on effect size harmonization see Ringquist (2013) chapter three "Calculating and Combining Effect Sizes".
} 
Table I: Variable summary statistics

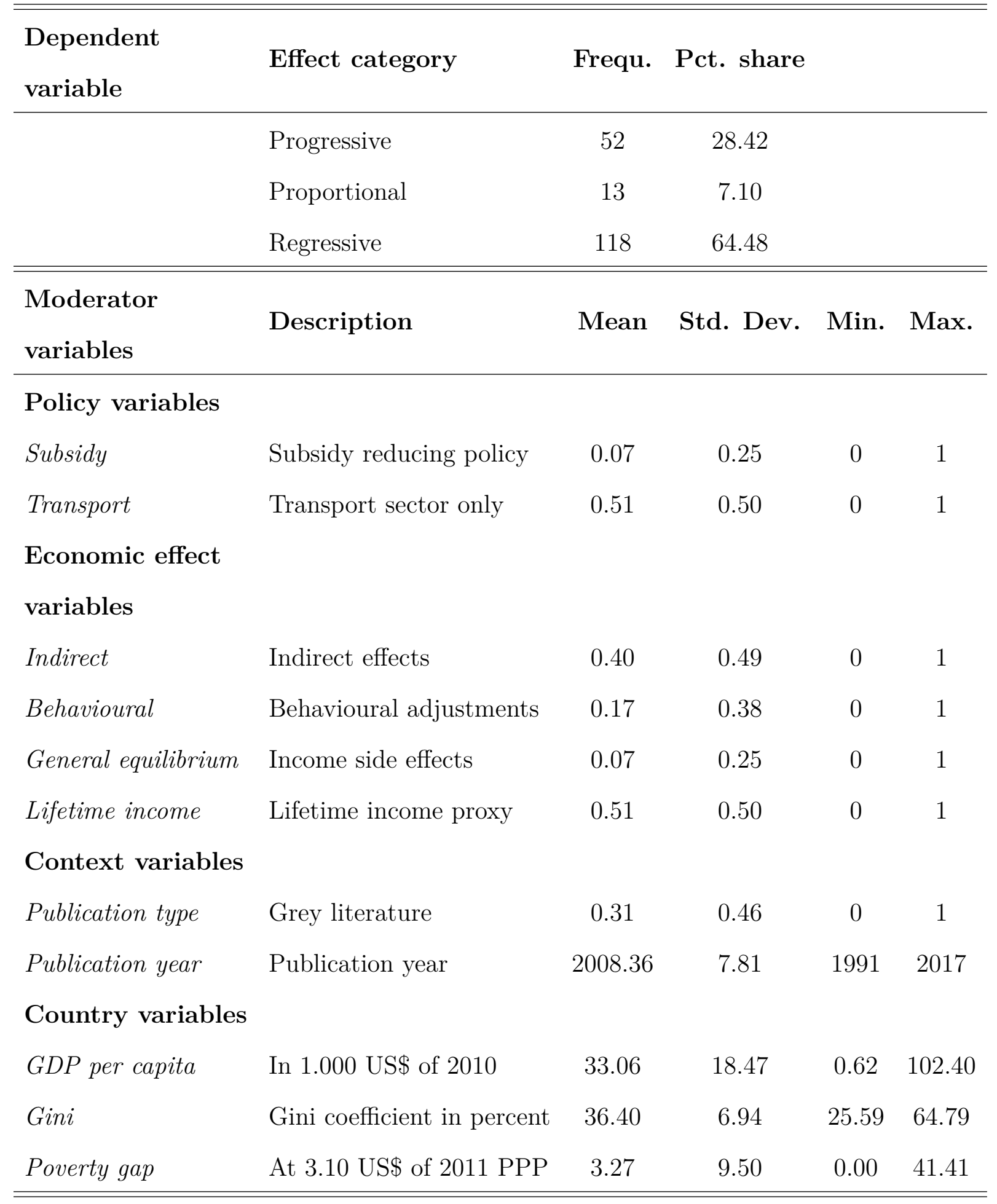


variables implicitly capture different study designs. We also control for a potential publication bias and a time trend. Table I summarizes the variables included. Furthermore, we test the bivariate relationship between the moderator variables and the dependent variable. For the binary moderator variables we conduct a two-proportion z-test. Similarly, we conduct a correlation analysis for the continuous moderator variables. The results of the two tests indicate an overall suitable selection of moderator variables. Further analysis, however, requires a multiple regression analysis as the bivariate tests ignore potential correlations between the moderator variables. The remainder of this section briefly explains the moderator variables included. More details about individual moderator variables and the bivariate analyses, including their results tables, are provided in Appendix A.3.

Policy variables: We include two variables controlling for policy differences: The Subsidy variable differs between subsidy reforms and carbon pricing schemes. The Transport variable compares policies only on the transport sector with economy-wide policies. Generally, we only include effects increasing the burden for households, i.e. only carbon pricing increases or introductions as well as subsidy decreases or removals.

Economic effect variables: We include four moderator variables which account for different economic effects: Indirect, Behavioural, General equilibrium and Lifetime income. The first three variables correspond to the model types used in the original studies while lifetime income proxies reflect differences in the underlying data. We explicitly include moderator variables on the modeled economic effects and not on the model type. This method allows us to extract more information from the original studies. Many authors, for example, using Input-Output models separately report both the direct and the indirect distributive impact. We however disregard information on the impact of the different model types themselves.

Each model type at least considers direct effects. We identify and include three major groups of more advanced models in the literature: Input-Output models, micro-simulation 
models and computable general equilibrium (CGE) models ${ }^{7}$. The Indirect variable covers the joint impact of direct and indirect effects and comprises findings from Input-Output and CGE models. The Behavioural variable covers behavioural changes in the demand of different income groups which are considered by micro-simulations and CGE models. The General equilibrium variable covers the long term general equilibrium effects and thus the income source side which are only analyzed by CGE models. The Lifetime income effects variable accounts for effects considering lifetime income proxies as opposed to annual household incomes.

Context variables: The Publication type variable differs between peer-reviewed journal articles and grey literature. The Publication year variable accounts for a potential time trend of study outcomes.

Country variables: We address the panel structure of our dataset by including timefixed and time-variant country dummies and variables. Our main specification includes 38 $(N-1, N=39)$ single country dummies that account for unobservable time-fixed country effects. It also includes three time-variant country variables: the GDP per capita, the Gini and the Poverty gap variable. These variables control for the country income and its distribution. For additional robustness checks, we group the countries based on the world bank country income level classifications, namely high, upper-middle, lower-middle and low-income countries. The country data originates from the World Bank dataset between the years 1990 and $2014^{8}$ (World Bank, 2017).

\subsection{Ordered probit model}

The bivariate analyses indicate a significant impact of most moderator variables on the dependent variable (see Appendix A.3). Identifying the isolated influence of each moderator variable, however, requires a regression analysis. The ordered categorical dependent variable with the outcomes progressive, proportional and regressive suggests the application of an ordered probit model. The approach is based on Greene (2012) and methodologi-

\footnotetext{
${ }^{7}$ Wang et. al. (2016) further list econometric models as a group. Due to their specific design and their rare occurrence we omit them from this analysis. Further details on the three model types are described in Appendix A.4.

${ }^{8}$ We adjust the data as further described in Appendix A.3.
} 
cally similar to the meta-analyses of Waldorf and Byun (2005), Card et al. (2009) and Wehkamp et al. (2018).

This ordered probit model uses a continuous latent variable $y^{*}$ to measure the unobserved effect size of each original study. We assume $y^{*}$ to be correlated with the three observed distributional effects: progressive $(y=0)$, proportional $(y=1)$ and regressive $(y=2)$. Suppressing the observation-specific index, the relationship between $y^{*}$ and the moderator variables $X$ is assumed to follow a linear regression model of the form

$$
y^{*}=X \beta+\epsilon
$$

with $y^{*}$ potentially varying between $-\infty$ and $\infty$ and $\epsilon$ being a normally distributed error term. The observed distributional impact $y$ is linked to the underlying latent variable $y^{*}$ by

$$
\begin{array}{lll}
y=0 & \text { if } & y^{*}<0 \\
y=1 & \text { if } & 0<y^{*}<\mu_{1} \\
y=2 & \text { if } & \mu_{1}<y^{*}
\end{array}
$$

where $\mu_{1}$ is an unknown threshold parameter simultaneously estimated with $\beta$.

The probability of estimating a progressive $(y=0)$, proportional $(y=1)$ or regressive $(y=2)$ distributional effect is given by

$$
\begin{aligned}
& P(y=0 \mid X)=\Phi(-X \beta) \\
& P(y=1 \mid X)=\Phi\left(\mu_{1}-X \beta\right)-\Phi(-X \beta) \\
& P(y=2 \mid X)=1-\Phi\left(\mu_{1}-X \beta\right)
\end{aligned}
$$

where $\Phi$ denotes the standard normal cumulative distribution function. We estimate the parameters by the maximum likelihood method with the previously described probabilities entering the likelihood function. The beta coefficients in combination with the $\mathrm{p}$-value provide the direction and the significance of the effect; a positive $\beta$ coefficient suggests that the respective moderator variable $X$ increases the probability of obtaining a regressive outcome $(P(y=2))$. Vice versa, a negative $\beta$ coefficient suggests that the re- 
spective moderator variable $X$ increases the probability of finding a progressive outcome $(P(y=0))$. The coefficients have an ambiguous effect on the probability of finding a proportional outcome $(P(y=1))$. The marginal effects at means show the magnitude of the probability change for the three possible outcomes induced by the moderator variables. The pseudo- $R^{2}$ is reported as a measure of fit (McFadden, 1974).

We conduct several sensitivity analyses and specification tests as proposed by the best-practice guideline for future meta-analysis by Nelson and Kennedy (2009). First, we impose cluster-robust standard errors by country to address non-independence of observations. Second, our dataset contains only a few observations and thus a low time variation for several countries which imposes the risk of multicollinear time-fixed and time-variant variables. We thus alter our model by assuming fixed-effects for country income groups instead for single countries and also by omitting country fixed effects to investigate their overall impact. Furthermore, we test several combinations of the time-variant country variables. Third, we test the validity of the ordered probit model specification by conducting significantly progressive and regressive probit regressions. Fourth, we use a jackknife method to identify the impact of single countries on the results (Gould, 1995). Finally, we test for multicollinearity using the variance inflation factors and the joint significance of the variable groups using the likelihood-ratio test. Appendix A.5 provides more details about the sensitivity analyses and specification tests.

\section{Results}

Table II shows the regression results of our main ordered probit model specification which includes the single country dummies and robust standard errors clustered by countries. The first column provides the estimated coefficients, the subsequent three columns present the marginal effects at mean for the three possible original study outcomes. A negative coefficient indicates an increased probability of a progressive study outcome. 
Table II: Ordered probit results

Marginal Effect

Moderator Variable Coefficient Regressive Proportional Progressive

Policy variables

Subsidy

0.211

0.084

$-0.012$

$-0.072$

Transport

$-1.405^{* *}$

$-0.559^{* *}$

0.081

$0.477^{* * *}$

Economic effect

variables

Indirect

$-0.628^{* *}$

$-0.250^{* *}$

0.036

$0.214^{* *}$

Behavioural

$-0.778^{*}$

$-0.309^{*}$

0.045

$0.264^{*}$

General equilibrium

0.028

0.011

$-0.002$

$-0.010$

Lifetime income

$-1.254^{*}$

$-0.499^{*}$

0.073

$0.426^{* *}$

Context variables

Publication type

$$
-0.558
$$

$-0.222$

0.032

0.189

Publication year

0.069

0.027

$-0.004$

$-0.023$

Country variables

GDP per capita

$-0.107$

$-0.042$

0.006

0.036

Gini

$-0.198$

$-0.079$

0.011

0.067

Poverty gap

$-0.879^{* * *}$

$-0.349^{* * *}$

$0.051^{*}$

$0.299^{* * *}$

Single Country

Dummies

$\begin{array}{llll}\text { yes yes yes } & \text { yes }\end{array}$

\begin{tabular}{ll}
\hline Cut 1 & 124.509 \\
Cut 2 & 124.999 \\
\hline Pseudo- $R^{2}$ & 0.507 \\
\hline \hline
\end{tabular}

Cluster-robust standard errors

Dep. var.: Distributional impact: $0=$ progressive, $1=$ proportional, $2=$ regressive

${ }^{*} p<0.10,{ }^{* *} p<0.05,{ }^{* * *} p<0.01$ 
Figure 3 additionally plots the coefficients for the most relevant alternative model specifications, i.e. regressions with single country dummies, group country dummies and no country dummies. For all three regression types we show the results with and without the three time-variant country variables ("Baseline" and "No Country Variables"). General findings from all robustness checks are discussed in Section 4.5. For a better overview we report the 38 coefficients of the single country dummies separately in the Appendix A.8.

The results confirm our hypotheses of a significantly increased likelihood for progressive study outcomes of transport policies, within lower income countries and for studies applying lifetime income proxies. In contrast, we show that studies on subsidy reforms are not inherently more progressive than carbon pricing instruments. The regression results show no impact of studies considering general equilibrium effects, while modeling indirect effects and behavioural adjustments of consumers provide more progressive study outcomes. The next subsections discuss the results for the different variable groups in detail.

\subsection{Policy variables}

We hypothesize that the two policy variables Subsidy and Transport will foster progressive outcomes; the Transport coefficient indeed indicates a significantly higher likelihood of progressive outcomes while the Subsidy coefficient is insignificant. Both findings are highly robust among most other model specifications (see Figure 3).

The insignificant finding for the Subsidy coefficient sharply contrasts with other literature findings but supports standard economic theory; as subsidies are equal to negative taxes (Varian, 2009), the impact of subsidies should be no systematically different to that of taxes or cap-and-trade systems, after controlling for all other influences. The finding is robust over all other specifications besides one notable exception; the regression with no country dummies and no country variables shows a highly significant negative coefficient indicating more progressive results for subsidies as previously expected. Again, energy subsidies have primarily been implemented in developing countries (Coady et al., 2015). Accordingly, our sample only includes subsidy policies in non high-income countries, such 
as India, Mali, Mexico, Nigeria, Poland and Turkey. We thus reason that the country variables capture the progressive impact of subsidy reforms.

Figure 3: Results overview

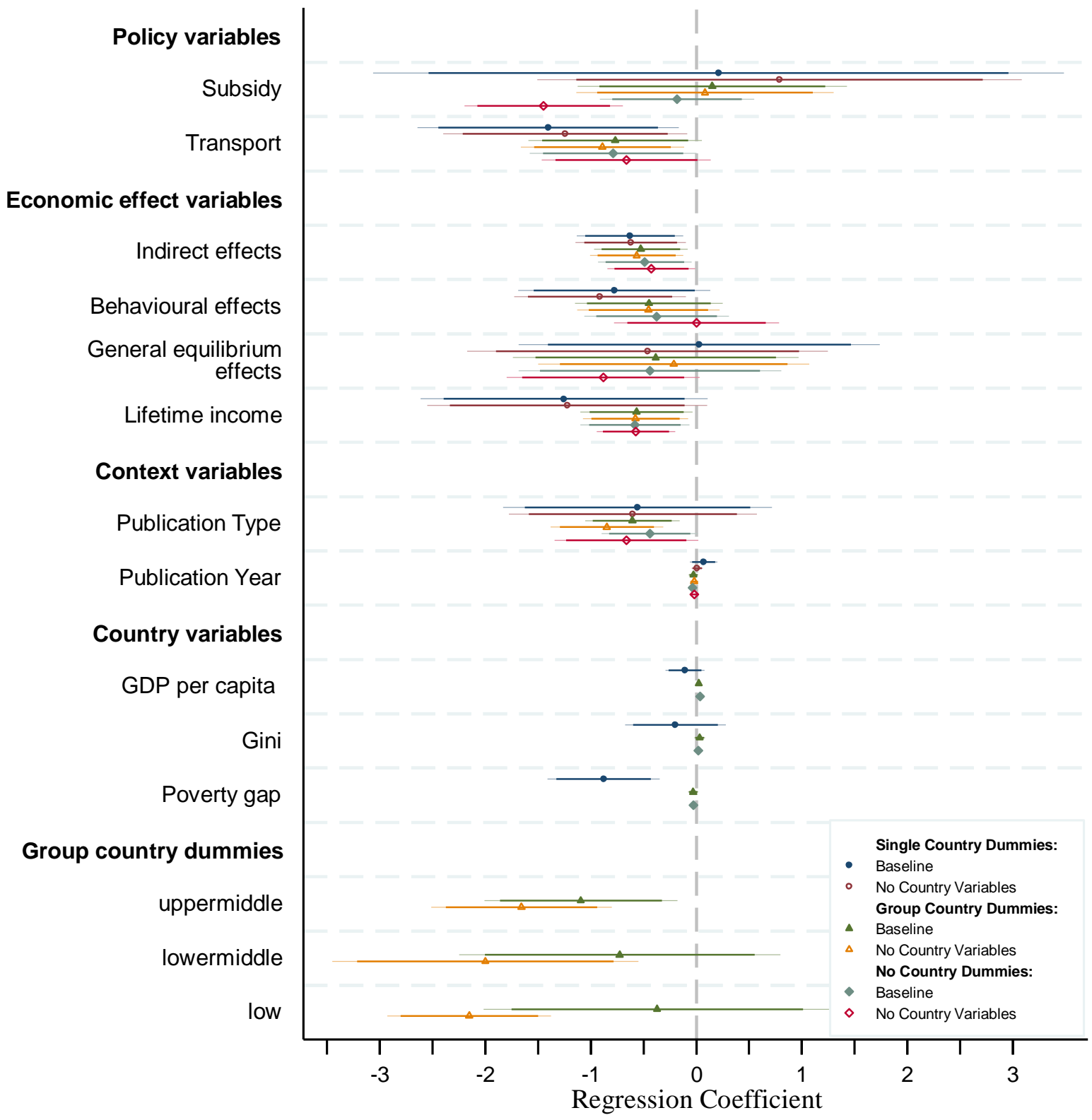

The Transport coefficient indicates a significantly and highly increased likelihood of progressive outcomes, as hypothesized. The marginal effects at mean show an increased likelihood of progressive outcomes of $44.7 \%$, and a $55.9 \%$ decreased likelihood of regressive outcomes, at the $1 \%$ and $5 \%$ significance levels. Most robustness checks confirm this finding though the magnitude of the effect decreases for regressions without single country 
dummies. Again, one notable exception is the regression with no country dummies and variables which shows an insignificant coefficient. This finding corresponds with the ambiguous literature outcomes which mostly show progressive but also regressive impacts in primarily high-income countries.

\subsection{Economic effect variables}

We hypothesize a progressive impact of the Lifetime income and the General equilibrium variables while being inconclusive about the Indirect and the Behavioural variables. Table II confirms that the application of Lifetime income proxies increases the likelihood of progressive findings. Progressive findings are also more likely in studies including Indirect and Behavioural effects. The General equilibrium coefficient is insignificant which contradicts our hypothesis.

The marginal effects at means for the Lifetime income variable indicate an increasing likelihood of progressive outcomes by $42.6 \%$. Regressive outcomes are $49.9 \%$ less likely. The results confirm the theory and are supported by the robustness checks. The magnitude of the coefficient, however, decreases for all regressions without single country dummies, though the significance level increases from $10 \%$ to $5 \%$.

The marginal effects for the Indirect variable indicate an increasing likelihood for progressive outcomes by $21.4 \%$. Regressive outcomes are $25 \%$ less likely at the $5 \%$ significance level. Other model specifications consistently show coefficients of slightly smaller magnitudes at mostly the same significance level. Previous literature findings show both increasing and decreasing regressivity of indirect effects (see Section 2). The results suggest more $\mathrm{CO}_{2}$-intensive consumption baskets of richer households.

The Behavioural variable increases the likelihood of progressive outcomes by $26.4 \%$ while regressive outcomes are $30.9 \%$ less likely. Robustness checks including single dummy variables show mostly significant coefficients at the 5 or $10 \%$ level except when standard errors are clustered by studies. Without the single country dummies the coefficients become insignificant. The progressive effect of the Behavioural variable is thus sensitive to the modeling of unobserved country characteristics. Though our findings suggest 
larger elasticities for high-income households, additional and country-specific research is recommended.

The General equilibrium coefficient remains insignificant over most model specifications. This finding strictly contradicts our hypothesis. One explanation would be the small number of general equilibrium effects included, in combination with our categorical dependent variable; CGE models are the only model type capturing general equilibrium effects. Many CGE models in the literature, however, include revenue recycling schemes which we exclude from this analysis. Our sample thus only contains 12 effects from CGE models of which $50 \%$ show regressive outcomes (see Table IV). The ordered categorical dependent variable only considers the overall outcome, i.e. regressive, proportional or progressive. We thus do not account for changes within each category, e.g. from strongly to weakly regressive. Therefore, we do not account for the presumably progressive source side effects within those six overall regressive outcomes. We further elaborate the implications of using a categorical dependent variable in Section 5.

Summing up, including a wider range of economic effects mostly fosters more progressive outcomes. The economic effects either reflect the application of more sophisticated model types or a different data base using lifetime income proxies.

\subsection{Context variables}

Table II neither shows a publication bias, nor a time trend. The Publication Type coefficients remain insignificant over model specifications including single country dummies. The robustness checks without single country dummies, however, indicate a publication bias towards more progressive outcomes. The Publication Year coefficients are insignificant over most model specifications though there are two significant coefficients with opposite signs. The two-proportion z-test results suggest a progressive publication bias and a time trend towards more progressive outcomes (see Appendix A.3). In fact, the grey literature included primarily investigates developing countries. Furthermore, research on developing countries has been increasing over recent years. The findings suggest that the country variables, and especially the single country dummies, account for both trends. 


\subsection{Country variables}

The regression results support our hypothesis of more progressive study outcomes for countries with lower income levels. Our main regression includes 38 single country dummies and three country variables accounting for time-fixed and time-variant country characteristics, respectively. The interpretation of the results of this variable group requires a particularly detailed investigation of the regression outputs.

Table II shows a significantly negative coefficient for the Poverty gap variable as expected. The finding indicates a higher likelihood of progressive outcomes for very poor or unequal countries. The coefficient, however, becomes small or insignificant for regressions without single country dummies. The finding is further sensitive to the countries included (see Section 4.5). The Gini coefficient is insignificant for all regressions. The GDP per capita coefficients are mostly insignificant in regressions with single country dummies which contradicts our hypothesis (see Appendix A.6).

An increased likelihood of progressive impacts in lower income countries is, however, clearly indicated by additional model specifications. The insignificant GDP per capita coefficients can be explained by the small temporal variation of the country variables, as the sample includes only a few observations for particularly low-income countries. The reduced temporal variation evokes multicollinear time-variant country variables and time-fixed single country dummies. The coefficients for the single country dummies and the country variables are thus inefficient for the main model specification. We address this problem by estimating another model that replaces the country group dummies with the single country dummies and another version which excludes the time-variant country variables. All model specifications without single country dummies, i.e. with country group dummies or without any country dummies, show significantly positive GDP per capita coefficients which implies more regressive study outcomes for richer countries. The regression coefficients for our specification with country group dummies but without country variables confirm this finding; the three group dummies coefficients (upper-middle, lower-middle and low) are significantly negative and increase in magnitude for decreasing income levels of the country groups. 


\subsection{Robustness checks}

We conduct several additional analyses to validate our findings. In particular, we address non-independence of observations, the influence of single countries and the validity of the ordered probit model specification. Furthermore, we test the robustness of the results with respect to different combinations of country variables. Appendix A.6 provides an overview of the regression results including all robustness checks. The last two columns show the results of the significantly regressive and progressive probit estimates. Again, the single country dummy coefficients are separately reported in the Appendix A.8.

We address non-independence of observations by imposing cluster-robust standard errors by country for every regression. Additionally we test the sensitivity of the standard errors to the clustering decision by imposing cluster-robust standard errors by study. Clustering by study shows broadly similar significance levels for most coefficients. Notable exceptions are the insignificant coefficient for the Behavioural variable and the significant coefficients for the Publication Year and the GPD per capita variables. We conclude that the clustering decision has a slight influence on the results. The overall findings however remain unchanged.

We test the influence of single countries on the results by conducting jackknife regressions (Gould, 1995). The jackknife method performs N regressions by leaving out the jth observations where $\mathrm{j}=1,2, \ldots, \mathrm{N}$ is the number of each country $(\mathrm{N}=39)$. Appendix A.7 shows the distribution of the $\mathrm{N}$ jackknife coefficients for each moderator variable including fitted normal distributions. The coefficients outside the $99 \%$ confidence interval unsurprisingly mostly correspond to countries with large numbers of effects, i.e. the United States and the United Kingdom. Most coefficients however remain similar in sign or overall magnitude besides the Subsidy and the Poverty gap coefficients. Omitting Brazil or Poland strongly influences these two coefficients as the sample contains just a few effects from lower income countries while both variables only have few positive observations. These two outlier countries have no impact on jackknife regressions for model specifications without single country dummies. 
Finally we investigate the validity of our ordered probit model specification by conducting probit regressions on significantly regressive and progressive outcomes. The coefficients of the significantly regressive probit regression are close to the ordered probit model coefficients. The significantly progressive probit coefficients are broadly opposite in sign. The findings indicate a valid ordered probit model specification.

\section{Discussion and Conclusion}

Market-based climate mitigation policies often raise concerns about potentially adverse distributional impacts. Distributional impacts have therefore been subject to various research papers finding regressive, proportional or progressive results. This meta-analysis provides valuable insights into the outcome heterogeneity in the distributional literature concerning climate mitigation policies. Increased knowledge about the distributional impacts of market-based climate mitigation policies not only allows us to determine potentially adverse distributional impacts, but also lays the foundation for addressing them.

To systematically determine the sources of variation across outcomes, this study applies an ordered probit meta-analysis framework on 53 original studies. We find a significantly increased likelihood of progressive study outcomes within lower income countries and for transport policies. The same applies to study designs considering indirect effects, behavioural adjustments of consumers or lifetime income proxies. In contrast, we show that studies on subsidy removing policies are not inherently more progressive than studies on carbon pricing.

The interpretation of the results should particularly consider the following limitations of the analysis. Disregarding the effect size of overall regressive, proportional or progressive distributional impacts influences the regression coefficients. Our methodology does not account for differences within outcome categories, for example between strongly and weakly regressive effects. Smaller changes in the distributional impact within single studies, which are mostly driven by the economic effect variables, are thus ignored. This results in downward biased and less significant coefficients, as illustrated by the General equilibrium coefficient. Likewise, treating similar distributional impacts between studies equally, irrespective of their magnitudes, might ambiguously influence the size and sig- 
nificance of the coefficients. Estimating the effect size using subsamples with common and thus quantitatively comparable inequality metrics, however, suffers from too few observations to be representative.

Finally, the small number of effects for lower income countries decreases the accuracy of our findings. Our analysis shows a large impact of two lower income countries on two variables (see Section 4.5). A higher proportion of effects on lower income countries in combination with a larger total sample would reduce the impact of outliers, allow for more refined moderator variables, and thus provide more precise insights. We thus recommend future researcher to put an emphasis on distributional impacts in lower income countries. The robustness checks, however, confirm the overall validity of our findings.

It should be noted, that even progressive policies increase consumer prices, which raises the risk of poverty for low-income households. In the most extreme cases this may lead to public resistance as illustrated by the example of Nigeria in 2012. The risk of poverty can, however, be offset by suitable revenue recycling schemes that compensate poor households (van Heerden et al., 2006). Progressive effects hence do not automatically mean that carbon pricing schemes would be acceptable for the poorest parts of the population. Hence, revenue recycling schemes might be needed in any case to alter the distributional and other impacts of climate mitigation policies.

Revenue recycling can also provide various other benefits. For example, using revenues to reduce distorting income taxes can potentially lead to more employment, higher individual welfare and higher GDP growth (Pearce, 1991; Goulder, 1995; Pezzey and Park, 1998). Revenues can also be used for public investments in infrastructure, providing access to water, sanitation, electricity, telecommunications and transport (Jakob et al., 2016). Climate policies in combination with a targeted use of revenues thus have the potential to simultaneously mitigate climate change and address additional sustainable development goals.

This study contributes to an increased understanding of the distributional impacts or the potential benefits of climate mitigation policies, which may further support their implementation. Thus far, there has been a widespread belief that consumption taxes, 
and particularly environmental taxes, would particularly impose a burden on the poor. However, more than one third of the effects included in this sample are progressive or proportional. Hence, distributional outcomes of market-based climate policies depend on a variety of (often country-specific) factors. This kind of research may thus help prevent actors with vested interests, such as investors fearing stranded assets or workers fearing job losses (Vogt-Schilb and Hallegatte, 2017), from instigating a public opposition against unwanted policies. 


\section{References}

Agostini, C. A. and Jiménez, J. (2015). The distributional incidence of the gasoline tax in Chile. Energy Policy, 85:243-252.

Anand, R., Coady, D., Mohommad, A., Thakoor, V. V., and Walsh, J. P. (2013). The Fiscal and Welfare Impacts of Reforming Fuel Subsidies in India. IMF Working Paper 13/128, International Monetary Fund.

Araar, A., Dissou, Y., and Duclos, J.-Y. (2011). Household incidence of pollution control policies: A robust welfare analysis using general equilibrium effects. Journal of Environmental Economics and Management, 61(2):227-243.

Banks, J., Blundell, R., and Lewbel, A. (1997). Quadratic Engel Curves And Consumer Demand. The Review of Economics and Statistics, 79(4):527-539.

Baranzini, A., Goldemberg, J., and Speck, S. (2000). A future for carbon taxes. Ecological Economics, 32(3):395-412.

Baumol, W. J. and Oates, W. E. (1988). The Theory of Environmental Policy. Cambridge University Press, 2. edition.

Beck, M., Rivers, N., Wigle, R., and Yonezawa, H. (2015). Carbon tax and revenue recycling: Impacts on households in British Columbia. Resource and Energy Economics, 41:40-69.

Bento, A. M., Goulder, L. H., Jacobsen, M. R., and von Haefen, R. H. (2009). Distributional and Efficiency Impacts of Increased US Gasoline Taxes. American Economic Review, 99(3):667-699.

Blackman, A., Osakwe, R., and Alpizar Rodriguez, F. (2010). Fuel tax incidence in developing countries: The case of Costa Rica. Energy Policy, 38(5):2208-2215.

Brenner, M., Riddle, M., and Boyce, J. K. (2007). A Chinese sky trust?: Distributional impacts of carbon charges and revenue recycling in China. Energy Policy, 35(3):17711784 . 
Brännlund, R. and Nordström, J. (2004). Carbon tax simulations using a household demand model. European Economic Review, 48(1):211-233.

Bull, N., Hassett, K. A., and Metcalf, G. E. (1994). Who Pays Broad-Based Energy Taxes? Computing Lifetime and Regional Incidence. The Energy Journal, 15(3):145164.

Burtraw, D., Sweeney, R., and Walls, M. (2009). The Incidence of U.S. Climate Policy: Alternative Uses of Revenues from a Cap-and-Trade Auction. National Tax Journal, 62(3):497-518.

Card, D., Kluve, J., and Weber, A. (2009). Active Labor Market Policy Evaluations: A Meta-Analysis. Technical Report 4002, Institute for the Study of Labor (IZA).

Casler, S. D. and Rafiqui, A. (1993). Evaluating Fuel Tax Equity: Direct and Indirect Distributional Effects. National Tax Journal, 46(2):197-205.

Chernick, H. and Reschovsky, A. (1997). Who Pays the Gasoline Tax? National Tax Journal, 50(2):233-259.

Chernick, H. and Reschovsky, A. (2000). Yes! Consumption Taxes Are Regressive. Challenge, 43(5):60-91.

Clements, B., Coady, D., Fabrizio, S., Gupta, S., Alleyne, T., and Sdralevich, C. (2013). Energy Subsidy Reform : Lessons and Implications. International Monetary Found.

Coady, D., Parry, I., Sears, L., and Shang, B. (2015). How Large Are Global Energy Subsidies? IMF Working Paper 15/105, International Monetary Fund.

Cornwell, A. and Creedy, J. (1996). Carbon Taxation, Prices and Inequality in Australia. Fiscal Studies, 17(3):21-38.

Creedy, J. and Sleeman, C. (2006). Carbon taxation, prices and welfare in New Zealand. Ecological Economics, 57(3):333-345. 
da Silva Freitas, L. F., de Santana Ribeiro, L. C., de Souza, K. B., and Hewings, G. J. D. (2016). The distributional effects of emissions taxation in Brazil and their implications for climate policy. Energy Economics, 59:37-44.

Datta, A. (2010). The incidence of fuel taxation in India. Energy Economics, 32:26-33.

Deaton, A. and Muellbauer, J. (1980). An Almost Ideal Demand System. The American Economic Review, 70(3):312-326.

Dinan, T. M. and Rogers, D. L. (2002). Distributional Effects of Carbon Allowance Trading: How Government Decisions Determine Winners and Losers. National Tax Journal, 55(2):199-221.

Dissou, Y. and Karnizova, L. (2016). Emissions cap or emissions tax? A multi-sector business cycle analysis. Journal of Environmental Economics and Management, 79:169188.

Dissou, Y. and Siddiqui, M. S. (2014). Can carbon taxes be progressive? Energy Economics, 42:88-100.

Dorband, I. I., Jakob, M., and Steckel, J. C. (2017). Double Progressivity of Infrastructure Development through Carbon Pricing - Insights from Nigeria. SSRN Scholarly Paper ID 3059138, Social Science Research Network, Rochester, NY.

Dresner, S. and Ekins, P. (2006). Economic Instruments to Improve UK Home Energy Efficiency without Negative Social Impacts. Fiscal Studies, 27(1):47-74.

Feng, K., Hubacek, K., Guan, D., Contestabile, M., Minx, J., and Barrett, J. (2010). Distributional Effects of Climate Change Taxation: The Case of the UK. Environmental Science $\mathscr{E}$ Technology, 44(10):3670-3676.

Fischer, C. and Newell, R. G. (2008). Environmental and technology policies for climate mitigation. Journal of Environmental Economics and Management, 55(2):142-162.

Flues, F. and Thomas, A. (2015). The distributional effects of energy taxes. OECD Taxation Working Papers, 23. OECD Publishing, Paris. 
Flues, F. and van Dender, K. (2017). The impact of energy taxes on the affordability of domestic energy. OECD Taxation Working Papers, 30. OECD Publishing, Paris.

Freund, C. L. and Wallich, C. I. (1996). The Welfare Effects of Raising Household Energy Prices in Poland. The Energy Journal, 17(1):53-77.

Friedman, M. (1957). A Theory of the Consumption Function. National Bureau of Economic Research, Inc.

Fullerton, D. and Heutel, G. (2011). Analytical General Equilibrium Effects of Energy Policy on Output and Factor Prices. The B.E. Journal of Economic Analysis 6 Policy, 10(2):1-26.

Fullerton, D. and Rogers, D. L. (1993). Who bears the lifetime tax burden? Brookings Institution, Washington, D.C.

G20 Leaders Statement (2009). G20 Leaders Statement: The Pittsburgh Summit. Technical report, Pittsburgh.

Gonzalez, F. (2012). Distributional effects of carbon taxes: The case of Mexico. Energy Economics, 34(6):2102-2115.

Gould, W. (1995). Jackknife estimation. Stata Technical Bulletin, 24:25-29. Retrieved from: https://www.stata.com/products/stb/journals/stb24.pdf. Last checked: 31.12 .2017

Goulder, L. (1995). Environmental taxation and the double dividend: A reader's guide. International Tax and Public Finance, 2(2):157-183.

Grainger, C. A. and Kolstad, C. D. (2010). Who Pays a Price on Carbon? Environmental and Resource Economics, 46(3):359-376.

Greene, W. H. (2012). Econometric Analysis. Pearson, Boston, 7 edition.

Grottera, C., Pereira, A. O., and La Rovere, E. L. (2017). Impacts of carbon pricing on income inequality in Brazil. Climate and Development, 9(1):80-93. 
Hamilton, K. and Cameron, G. (1994). Simulating the Distributional Effects of a Canadian Carbon Tax. Canadian Public Policy / Analyse de Politiques, 20(4):385-399.

Hassett, K. A., Mathur, A., and Metcalf, G. E. (2009). The Incidence of a U.S. Carbon Tax: A Lifetime and Regional Analysis. The Energy Journal, 30(2):155-177.

High-Level Commission on Carbon Prices (2017). Report of the High-Level Commission on Carbon Prices.

IEA (2017). Recent development of Energy Subsidies. Retrieved from: https://www.iea.org/media/publications/weo/Recentdevelopments_2017.pdf, Last checked: 22.12 .2017 .

IEA and OECD (2017). Update on recent progress in reform of inefficient fossil fuel subsidies that encourage wasteful consumption. Retrieved from: https://www.iea.org/media/g20/G20_SWG_FFSR_Update_March2017_IEAOECD.pdf. Last checked: 22.12 .2017 .

Inchauste, G. and Victor, D. G. (2017). The Political Economy of Energy Subsidy Reform. Directions in Development-Public Sector Governance. World Bank, Washington, D.C. IPCC (2014). Climate Change 2014: Synthesis Report. Contribution of Working Groups I, II and III to the Fifth Assessment Report of the Intergovernmental Panel on Climate Change. Technical report, IPCC, Geneva, Switzerland.

Jacobsen, H. K., Birr-Pedersen, K., and Wier, M. (2003). Distributional Implications of Environmental Taxation in Denmark. Fiscal Studies, 24(4):477-499.

Jakob, M., Chen, C., Fuss, S., Marxen, A., Rao, N. D., and Edenhofer, O. (2016). Carbon Pricing Revenues Could Close Infrastructure Access Gaps. World Development, 84:254265.

Kalkuhl, M., Edenhofer, O., and Lessmann, K. (2012). Learning or lock-in: Optimal technology policies to support mitigation. Resource and Energy Economics, 34(1):123. 
Kpodar, K. (2006). Distributional Effects of Oil Price Changes on Household Expenditures: Evidence from Mali. IMF Working Paper 06/91, International Monetary Fund.

Labandeira, X. and Labeaga, J. (1999). Combining input-output analysis and microsimulation to assess the effects of carbon taxation on Spanish households. Fiscal Studies, 20(3):305-320.

Labandeira, X., Labeaga, J. M., and Rodríguez, M. (2009). An integrated economic and distributional analysis of energy policies. Energy Policy, 37(12):5776-5786.

Leach, A. J. (2009). The welfare implications of climate change policy. Journal of Environmental Economics and Management, 57(2):151-165.

Lewbel, A. and Pendakur, K. (2009). Tricks with Hicks: The EASI Demand System. American Economic Review, 99(3):827-863.

Lockwood, M. (2015). Fossil Fuel Subsidy Reform, Rent Management and Political Fragmentation in Developing Countries. New Political Economy, 20(4):475-494.

Lyon, A. B. and Schwab, R. M. (1995). Consumption Taxes in a Life-Cycle Framework: Are Sin Taxes Regressive? The Review of Economics and Statistics, 77(3):389-406.

Mabugu, R., Chitiga, M., and Amusa, H. (2009). The economic consequences of a fuel levy reform in South Africa. South African Journal of Economic and Management Sciences, 12(3):280-296.

MacKenzie, I. A. and Ohndorf, M. (2012). Cap-and-trade, taxes, and distributional conflict. Journal of Environmental Economics and Management, 63(1):51-65.

Mathur, A. and Morris, A. C. (2014). Distributional effects of a carbon tax in broader U.S. fiscal reform. Energy Policy, 66:326-334.

McEvoy, D. M. and McGinty, M. (2018). Negotiating a uniform emissions tax in international environmental agreements. Journal of Environmental Economics and Management, 90:217-231. 
McFadden, D. (1974). The measurement of urban travel demand. Journal of Public Economics, 3(4):303-328.

Metcalf, G. (1999). A Distributional Analysis of Green Tax Reforms. National Tax Journal, 52(4):655-82.

Metcalf, G. E. (2009). Designing a Carbon Tax to Reduce U.S. Greenhouse Gas Emissions. Review of Environmental Economics and Policy, 3(1):63-83.

Moeltner, K., Boyle, K. J., and Paterson, R. W. (2007). Meta-analysis and benefit transfer for resource valuation-addressing classical challenges with Bayesian modeling. Journal of Environmental Economics and Management, 53(2):250-269.

Mutua, J. M., Börjesson, M., and Sterner, T. (2009). Transport choice, elasticity, and distributional effects of fuel taxes in Kenya. Critical issues in environmental taxation, $7: 167-186$.

Nelson, J. P. and Kennedy, P. E. (2009). The Use (and Abuse) of Meta-Analysis in Environmental and Natural Resource Economics: An Assessment. Environmental and Resource Economics, 42(3):345-377.

Nikodinoska, D. and Schröder, C. (2016). On the emissions-inequality and emissions-welfare trade-offs in energy taxation: Evidence on the German car fuels tax. Resource and Energy Economics, 44:206-233.

Nordhaus, W. D. (1991). A Sketch of the Economics of the Greenhouse Effect. The American Economic Review, 81(2):146-150.

Oye, K. A. and Maxwell, J. H. (1994). 8. Self-Interest and Environmental Management. Journal of Theoretical Politics, 6(4):593-624.

Parry, I. W. H. (2004). Are emissions permits regressive? Journal of Environmental Economics and Management, 47(2):364-387.

Parry, I. W. H. (2015). Carbon Tax Burdens on Low-Income Households: A Reason for Delaying Climate Policy? CESifo Working Paper Series 5482, CESifo Group Munich. 
Parry, I. W. H. and Williams, R. C. (2010). What are the Costs of Meeting Distributional Objectives for Climate Policy? The B.E. Journal of Economic Analysis 6 Policy, 10(2):(Symposium), Article 9.

Parry, I. W. H., Williams, R. C., and Goulder, L. H. (1999). When Can Carbon Abatement Policies Increase Welfare? The Fundamental Role of Distorted Factor Markets. Journal of Environmental Economics and Management, 37(1):52-84.

Pearce, D. (1991). The Role of Carbon Taxes in Adjusting to Global Warming. The Economic Journal, 101(407):938-948.

Pearson, M. and Smith, S. (1991). The European carbon tax: an assessment of the European Commission's proposals. Report R39, Institute for Fiscal Studies, London.

Pezzey, J. C. V. and Park, A. (1998). Reflections on the Double Dividend Debate. Environmental and Resource Economics, 11(3-4):539-555.

Pigou, A. C. (1920). The Economics of Welfare. Macmillan, London.

Poterba, J. M. (1989). Lifetime Incidence and the Distributional Burden of Excise Taxes. The American Economic Review, 79(2):325-330.

Poterba, J. M. (1991). Is the Gasoline Tax Regressive? Tax Policy and the Economy, $5: 145-164$.

Rahman, M. M. (2013). The carbon tax in Australia: impacts on income distribution, employment and competitiveness. Academy of Taiwan Business Management Review, $9(3): 12-19$.

Rausch, S., Metcalf, G. E., and Reilly, J. M. (2011). Distributional impacts of carbon pricing: A general equilibrium approach with micro-data for households. Energy Economics, 33:20-33.

Ringquist, E. (2013). Meta-Analysis for Public Management and Policy. John Wiley \& Sons, Hoboken, NJ, USA, 1 edition. 
Rosas-Flores, J. A., Bakhat, M., Rosas-Flores, D., and Fernández Zayas, J. L. (2017). Distributional effects of subsidy removal and implementation of carbon taxes in Mexican households. Energy Economics, 61:21-28.

Sajeewani, D., Siriwardana, M., and Mcneill, J. (2015). Household distributional and revenue recycling effects of the carbon price in australia. Climate Change Economics, 06(03):1-23.

Santos, G. and Catchesides, T. (2005). Distributional Consequences of Gasoline Taxation in the United Kingdom. Transportation Research Record: Journal of the Transportation Research Board, 1924:103-111.

Shah, A. and Larsen, B. (1992). Carbon taxes, the greenhouse effect, and developing countries. Policy Research Working Paper Series 957, World Bank.

Shammin, M. R. and Bullard, C. W. (2009). Impact of cap-and-trade policies for reducing greenhouse gas emissions on U.S. households. Ecological Economics, 68(8):2432-2438.

Shinkuma, T. and Sugeta, H. (2016). Tax versus emissions trading scheme in the long run. Journal of Environmental Economics and Management, 75:12-24.

Soile, I. and Mu, X. (2015). Who benefit most from fuel subsidies? Evidence from Nigeria. Energy Policy, 87:314-324.

Speck, S. (1999). Energy and carbon taxes and their distributional implications. Energy Policy, 27(11):659-667.

Stanley, T. D. and Doucouliagos, H. (2012). Meta-Regression Analysis in Economics and Business. Routledge, New York, 1 edition edition.

Sterner, T. (2012). Distributional effects of taxing transport fuel. Energy Policy, 41:7583.

Symons, E., Proops, J., and Gay, P. (1994). Carbon Taxes, Consumer Demand and Carbon Dioxide Emissions: A Simulation Analysis for the UK. Fiscal Studies, 15(2):1943. 
Teixidó, J. J. and Verde, S. F. (2017). Is the Gasoline Tax Regressive in the Twenty-First Century? Taking Wealth into Account. Ecological Economics, 138:109-125.

Tiezzi, S. (2005). The welfare effects and the distributive impact of carbon taxation on Italian households. Energy Policy, 33(12):1597-1612.

Tovar Reaños, M. A. and Wölfing, N. M. (2017). Household Energy Prices and Inequality: Evidence From German Microdata Based on the EASI Demand System. Energy Economics.

Tunçel, T. and Hammitt, J. (2014). A new meta-analysis on the WTP/WTA disparity. Journal of Environmental Economics and Management, 68(1):175-187.

van Heerden, J., Gerlagh, R., Blignaut, J., Horridge, M., Hess, S., Mabugu, R., and Mabugu, M. (2006). Searching for Triple Dividends in South Africa: Fighting $\mathrm{CO}_{2}$ pollution and poverty while promoting growth. The Energy Journal, 27(2):113-141.

Vandyck, T. and Van Regemorter, D. (2014). Distributional and regional economic impact of energy taxes in Belgium. Energy Policy, 72:190-203.

Varian, H. R. (2009). Intermediate Microeconomics: A Modern Approach. W. W. Norton \& Company, New York, 8 edition edition.

Verde, S. and Tol, R. S. J. (2009). The Distributional Impact of a Carbon Tax in Ireland. The Economic and Social Review, 40:317-338.

Vogt-Schilb, A. and Hallegatte, S. (2017). Climate policies and nationally determined contributions: reconciling the needed ambition with the political economy: Climate policies and nationally determined contributions. Wiley Interdisciplinary Reviews: Energy and Environment, 6:256.

Waldorf, B. and Byun, P. (2005). Meta-analysis of the impact of age structure on fertility. Journal of Population Economics, 18(1):15-40.

Wang, Q., Hubacek, K., Feng, K., Wei, Y.-M., and Liang, Q.-M. (2016). Distributional effects of carbon taxation. Applied Energy, 184:1123-1131. 
Wehkamp, J., Koch, N., Lübbers, S., and Fuss, S. (2018). Governance and deforestation - a meta-analysis in economics. Ecological Economics, 144:214-227.

West, S. E. and Williams, R. C. (2004). Estimates from a consumer demand system: implications for the incidence of environmental taxes. Journal of Environmental Economics and Management, 47(3):535-558.

Wier, M., Birr-Pedersen, K., Jacobsen, H. K., and Klok, J. (2005). Are CO2 taxes regressive? Evidence from the Danish experience. Ecological Economics, 52(2):239251.

Williams, R., Gordon, H., Burtraw, D., Carbone, J., and Morgenstern, R. D. (2015). The Initial Incidence of a Carbon Tax Across Income Groups. National Tax Journal, 68(1):195-214.

World Bank (2017). World Development Indicators. Retrieved from: http://databank.worldbank.org/data/reports.aspx?source=world-developmentindicators.

World Bank and Ecofys (2018). State and Trends of Carbon Pricing 2018. Technical report, Washington, D.C.

Yang, H.-Y. (2000). Carbon-reducing taxes and income inequality: general equilibrium evaluation of alternative energy taxation in Taiwan. Applied Economics, 32(9):12131221.

Yang, H.-Y. and Wang, T.-F. (2002). Social incidence and economic costs of carbon limits: a computable general equilibrium analysis for Taiwan. Applied Economics Letters, $9(3): 185-189$.

Yusuf, A. A. and Resosudarmo, B. P. (2015). On the distributional impact of a carbon tax in developing countries: the case of Indonesia. Environmental Economics and Policy Studies, 17(1):131-156. 
Zhang, F. (2015). Energy Price Reform and Household Welfare: The Case of Turkey. The Energy Journal, 36(2):71-95.

Ziramba, E., L. Kumo, W., and Akinboade, O. (2009). Economic instruments for environmental regulation in Africa: An analysis of the efficacy of fuel taxation for pullution control in South Africa. CEEPA Discussion Paper 44, Centre for Environmental Economics and Policy in Africa, University of Pretoria. 


\section{A Appendix for online publication}

\section{A.1 Search query}

We use different combinations of keywords to comprehensively identify a broad set of original studies for our analysis. Unsuitable categories (for Scopus) and keywords indicating unsuitable categories (for both literature databases) are directly excluded. Adapting the two search queries to the respective syntaxes gives:

\section{Web of Science:}

TS $=((($ carbon OR CO2 OR fuel OR gasoline OR emission* OR environment* OR ecologic* OR energy) NEAR/3 ("tax" OR "taxes" OR "taxation" OR allowance* OR subsid* OR polic* OR pric*)) NEAR/10 (distribut* OR regressive OR progressive OR incidence OR inequality OR (household* NEAR/1 income*))) NOT TS = ("smart grid" OR biomass OR (distribut* NEAR/1 (energ* OR network* OR spatial)) OR "power plant" OR "natural gas" OR health OR solar OR hydropower OR software OR wireless OR "computer" OR forest) NOT WC = ("engineering electrical electronic" OR "thermodynamics" OR zoology OR oceanography OR "engineering civil" OR "computer science theory methods")

\section{Scopus:}

TITLE-ABS-KEY(((carbon OR CO2 OR fuel OR gasoline OR emission* OR environment* OR ecologic* OR energy) W/3 (("tax" OR "taxes" OR "taxation" OR allowance* OR subsid* OR polic* OR pric*)) W/10 (distribut* OR regressive OR progressive OR incidence OR inequality OR "household income"))) AND NOT TITLE-ABS-KEY("smart grid“ OR biomass OR (distribut* W/1(energ* OR network* OR spatial)) OR "power plant" OR "natural gas" OR health OR solar OR hydropower OR software OR wireless OR "computer" OR forest) AND (EXCLUDE ( SUBJAREA,"COMP") OR EXCLUDE ( SUBJAREA,"MATH") OR EXCLUDE ( SUBJAREA,"CENG" )) 


\section{A.2 Study overview}

Table III: Study overview

\begin{tabular}{|c|c|c|c|}
\hline Authors & Yr. & Eff. & Pct. \\
\hline Agostini C.A., Jimenez J & 2015 & 2 & 1.09 \\
\hline $\begin{array}{l}\text { Anand R., Coady D.P., Mohommad A., Thakoor, V.J., } \\
\text { Walsh J.P. }\end{array}$ & 2013 & 1 & 0.55 \\
\hline Beck M., Rivers N., Wigle R., Yonezawa H. & 2015 & 2 & 1.09 \\
\hline $\begin{array}{l}\text { Bento A.M., Goulder L.H., Jacobsen M.R., } \\
\text { von Haefen R.H. }\end{array}$ & 2009 & 1 & 0.55 \\
\hline Blackman A., Osakwe R., Alpizar Rodriguez F. & 2010 & 2 & 1.09 \\
\hline Brenner M., Riddle M., Boyce J.K. & 2007 & 2 & 1.09 \\
\hline Bull N., Hasset K.A., Metcalf G.E. & 1994 & 4 & 2.19 \\
\hline Burtraw D., Sweeney R., Walls M. & 2009 & 2 & 1.09 \\
\hline Casler S.D., Rafiqui A. & 1993 & 6 & 3.28 \\
\hline Chernick H., Reschovsky A. & 1997 & 2 & 1.09 \\
\hline Chernick H., Reschovsky A. & 2000 & 2 & 1.09 \\
\hline Cornwell A., Creedy J. & 1996 & 1 & 0.55 \\
\hline Creedy, John; Sleeman, Catherine & 2006 & 1 & 0.55 \\
\hline Datta A. & 2010 & 2 & 1.09 \\
\hline Dinan T.M., Rogers D.L. & 2002 & 1 & 0.55 \\
\hline Dissou Y., Siddiqui M.S. & 2014 & 1 & 0.55 \\
\hline Dresner S., Ekins P. & 2006 & 1 & 0.55 \\
\hline $\begin{array}{l}\text { Feng K.S., Hubacek K., Guan D., Contestabile M., } \\
\text { Minx J., Barrett J. }\end{array}$ & 2010 & 1 & 0.55 \\
\hline Flues F., Thomas A. & 2015 & 41 & 22.40 \\
\hline Freund C.L., Wallich C.I. & 1996 & 4 & 2.19 \\
\hline Fullerton D., Heutel G. & 2011 & 4 & 2.19 \\
\hline Grainger C.A., Kolstad C.D. & 2010 & 4 & 2.19 \\
\hline Grottera C., Pereira A.O., La Rovere E.L. & 2017 & 1 & 0.55 \\
\hline Hamilton K., Cameron G. & 1994 & 2 & 1.09 \\
\hline Hassett K.A., Mathur A., Metcalf G.E. & 2009 & 12 & 6.56 \\
\hline Kpodar K. & 2006 & 2 & 1.09 \\
\hline Labandeira X., Labeaga J. & 1999 & 1 & 0.55 \\
\hline
\end{tabular}


Mabugu R., Chitiga M., Amusa H.

\begin{tabular}{rrr}
2009 & 1 & 0.55 \\
2014 & 5 & 2.73 \\
1999 & 4 & 2.19 \\
2009 & 1 & 0.55 \\
2009 & 2 & 1.09 \\
2016 & 2 & 1.09 \\
2010 & 2 & 1.09 \\
1991 & 8 & 4.37 \\
2011 & 1 & 0.55 \\
2017 & 2 & 1.09 \\
2015 & 1 & 0.55 \\
2005 & 1 & 0.55 \\
2016 & 1 & 0.55 \\
1992 & 2 & 1.09 \\
2009 & 1 & 0.55 \\
2015 & 2 & 1.09 \\
2012 & 26 & 14.21 \\
1994 & 1 & 0.55 \\
2017 & 2 & 1.09 \\
2004 & 2 & 1.09 \\
2005 & 6 & 3.28 \\
2000 & 1 & 0.55 \\
2002 & 1 & 0.55 \\
2015 & 1 & 0.55 \\
2015 & 1 & 0.55 \\
2009 & 1 & 0.55 \\
\hline & $\mathbf{1 8 3}$ & 100 \\
\hline & &
\end{tabular}




\section{A.3 Detailed moderator variable description}

Policy variables: The Subsidy variable includes all effects of studies modeling subsidy reforms. For this variable we allow for policies on single fuels while carbon taxes and capand-trade systems only consider economy-wide policies. The variable implicitly abstracts from differences between carbon tax policies and cap-and-trade systems and specific policy designs though both have been widely debated in the literature (Parry et al., 1999; Parry, 2004; Leach, 2009; Dissou and Karnizova, 2016; Shinkuma and Sugeta, 2016). The Transport variable includes all effects of studies on the transport sector alone. This includes higher prices for petrol, diesel or liquefied petroleum gas (LPG) explicitly used for transport purposes. To ensure comparability with other policies, we only include distributional impacts on all households, irrespective if they own a car or not.

Country variables and data: We measure the GDP per capita variable in steps of 1,000 US\$ in constant 2010 US\$. The Gini coefficient, as commonly applied to measure the distribution of income and wealth, takes values between 0 and 1. A higher Gini coefficient indicates a larger inequality. The Poverty gap variable measures the mean shortfall from the poverty line of 3.10 US $\$$ of 2011 PPP. It therefore simultaneously captures the amount of people below the poverty line as well as their distance to it. A higher value indicates a larger absolute poverty.

The four country dummies by income level refer to the GNI per capita in US $\$$ using the Atlas methodology. We use data from the World Bank World Development Indicators for the years 1990-2014 (World Bank, 2017). Further information on the dataset can be obtained from: https://data.worldbank.org/data-catalog/world-development-indicators.

We adjust our coded data or the dataset to consistently match the World Bank data for the countries included. First, we match the country data with the publication year of the original study's underlying household survey data, unless the authors provide an explicit reference year. As our dataset only contains data from 1990-2014, we truncate the reference year/household data publication year accordingly. Second, the dataset lacks time-consistent data on the gini coefficients and the poverty gap. We fill the gaps with the next available datapoint in the future. If there is no available datapoint, we use the 
last available datapoint. Third, as there is no available data for British Columbia and Taiwan we use data for Canada and China, respectively. Further information on the coding and the data are documented in the codebook which is available upon request.

Bivariate z-test: We test the bivariate relationship between the moderator variables and the dependent variable. For the binary moderator variables we conduct a two-proportion z-test. The test results indicate, if using the variable significantly changes the proportion of progressive, proportional or regressive study outcomes. Similarly we conduct a correlation analysis for the continuous moderator variables. The results indicate sign and significance of the correlation between the moderator variables and the dependent variable. Table IV shows the results for both tests.

The two-proportion z-test results indicate a significant impact of more than half of the binary moderator variables on the proportion of study outcomes. For instance, the share of progressive findings for studies modeling transport policies increases to $36.2 \%$ compared to $20.2 \%$ for studies on economy-wide policies. The correlation analysis shows a significant correlation between most continuous variables and the dependent variable. The results of the two tests indicate a reasonable selection of moderator variables. The bivariate tests however ignore potential correlations between the moderator variables.

Additional moderator variables: We exclude several potentially interesting moderator variables on policies and the study design. In particular, we neglect policy variables on revenue recycling schemes, levels of pricing and the impact of single fuels. The modeled revenue recycling schemes in the literature are too context specific to be aggregated to homogeneous groups. The impact of different pricing levels is especially relevant for CGE models covering behavioural and income side effects. The small number of CGE models included, however, prevents us from determining their quantitative impact. Covering the impact of single fuels would allow us to conduct a more disaggregated analysis. The distributional impact of single fuels is, however, too rarely and inconsistently reported to provide robust findings. We further exclude moderator variables on the study design for different household equivalence scales, lifetime income measures and inequality measurement units. The reasons for exclusion are: scarce reporting of equivalence scales; 
heterogeneous lifetime income proxies; and too few literature sources comparing different inequality measures. The following references explicitly discuss or compare the impact of the excluded moderator variables: revenue recycling schemes (Speck, 1999; Rausch et al., 2011; Mathur and Morris, 2014; Williams et al., 2015); level of pricing (Dissou and Siddiqui, 2014; Grottera et al., 2017); single fuels (Casler and Rafiqui, 1993; Jacobsen et al., 2003); equivalence scales (Grainger and Kolstad, 2010); lifetime income measures (Bull et al., 1994; Hassett et al., 2009) and inequality measurement units (Cornwell and Creedy, 1996; Nikodinoska and Schröder, 2016). 
Table IV: Moderator variables, effect types and correlations

\begin{tabular}{|c|c|c|c|c|c|}
\hline \multirow{2}{*}{$\begin{array}{l}\text { Binary } \\
\text { Moderator } \\
\text { Variables }\end{array}$} & & \multirow{2}{*}{$\begin{array}{l}\text { Number of } \\
\text { estimates }\end{array}$} & \multicolumn{3}{|c|}{ Proportion of estimates } \\
\hline & & & Regressive & Proportional & Progressive \\
\hline \multicolumn{6}{|c|}{ Policy variables } \\
\hline \multirow[t]{3}{*}{ Subsidy } & Yes & 12 & 0.333 & 0.076 & 0.667 \\
\hline & No & 171 & 0.667 & 0.000 & 0.257 \\
\hline & z-test & & $2.332^{* *}$ & 0.991 & $-3.039^{* * *}$ \\
\hline \multirow[t]{3}{*}{ Transport } & Yes & 94 & 0.553 & 0.085 & 0.362 \\
\hline & No & 89 & 0.742 & 0.056 & 0.202 \\
\hline & z-test & & $2.661^{* * *}$ & -0.761 & $-2.390^{* *}$ \\
\hline
\end{tabular}

Economic effect variables

$\begin{array}{lcllll}\text { Indirect } & \text { Yes } & 73 & 0.699 & 0.055 & 0.247 \\ & \text { No } & 110 & 0.609 & 0.082 & 0.309 \\ & \text { z-test } & & -1.239 & 0.697 & 0.918 \\ \text { Behavioural } & \text { Yes } & 32 & 0.625 & 0.125 & 0.250 \\ & \text { No } & 151 & 0.649 & 0.060 & 0.291 \\ & \text { z-test } & & 0.258 & -1.308 & 0.472 \\ \text { General equilibrium } & \text { Yes } & 12 & 0.500 & 0.167 & 0.333 \\ & \text { No } & 171 & 0.655 & 0.064 & 0.281 \\ \text { Lifetime income } & \text { Yes } & 93 & 1.084 & -1.334 & -0.391 \\ & \text { No } & 90 & 0.538 & 0.086 & 0.376 \\ \text { Z-test } & & 0.756 & 0.056 & 0.189 \\ \text { Publication type } & \text { Yes } & 57 & 3.080^{* * *} & -0.802 & -2.811^{* * *} \\ & \text { No } & 126 & & & \\ & \text { z-test } & & 0.474 & 0.123 & 0.404 \\ & & & 3.253^{* * *} & -1.834^{*} & -2.408^{* *}\end{array}$

Additionally:

Country Group

Dummies

$\begin{array}{rlllll}\text { High } & \text { Yes } & 144 & 0.771 & 0.063 & 0.167 \\ \text { No } & 39 & 0.179 & 0.103 & 0.718 \\ \text { z-test } & & -6.845^{* * *} & 0.864 & 6.771^{\text {*** }}\end{array}$




\begin{tabular}{|c|c|c|c|c|c|}
\hline \multirow[t]{3}{*}{ Upper-middle } & Yes & 18 & 0.167 & 0.111 & 0.722 \\
\hline & No & 165 & 0.697 & 0.067 & 0.236 \\
\hline & z-test & & $4.464^{* * *}$ & -0.697 & $-4.340^{* * *}$ \\
\hline \multirow[t]{3}{*}{ Lower-middle } & Yes & 9 & 0.222 & 0.111 & 0.667 \\
\hline & No & 174 & 0.667 & 0.069 & 0.264 \\
\hline & z-test & & $2.717^{* * *}$ & -0.480 & $-2.609^{* * *}$ \\
\hline \multirow[t]{3}{*}{ Low } & Yes & 12 & 0.167 & 0.083 & 0.750 \\
\hline & No & 171 & 0.678 & 0.070 & 0.251 \\
\hline & z-test & & $3.580^{* * *}$ & -0.172 & $-3.701^{* * *}$ \\
\hline \multicolumn{6}{|l|}{ Continuous } \\
\hline \multicolumn{6}{|l|}{ Moderator } \\
\hline \multicolumn{6}{|l|}{ Variables } \\
\hline Publication year & & 183 & -0.217 & $0.003^{* * *}$ & \\
\hline \multicolumn{6}{|c|}{ Country variables } \\
\hline GDP per capita & & 183 & 0.509 & $0.000^{* * *}$ & \\
\hline Gini & & 183 & -0.042 & 0.574 & \\
\hline Poverty gap & & 183 & -0.387 & $0.000^{* * *}$ & \\
\hline
\end{tabular}




\section{A.4 Original study model details}

Input-Output models cover direct and indirect price changes of different product categories. The indirect impact accounts for higher prices of goods and services using carbon intensive intermediate inputs by applying a static input-output matrix. This approach commonly assumes that levies are fully passed through to the final consumers. The assumption of inelastic demand corresponds to the short term incidence of higher prices (Hassett et al., 2009; Feng et al., 2010; Anand et al., 2013).

Micro-simulation models account for behavioural changes by considering consumer choices. The consumer demand is elastic with consumers maximizing their utility for given preferences, prices and budgets. Commonly used micro-simulation models are almost ideal demand systems (AIDS) (Deaton and Muellbauer, 1980; West and Williams, 2004; Tiezzi, 2005; Rosas-Flores et al., 2017); its more flexible quadratic specification (QAIDS) (Banks et al., 1997; Brännlund and Nordström, 2004; Nikodinoska and Schröder, 2016); or more recently the exact affine stone index (EASI) demand system (Lewbel and Pendakur, 2009; Tovar Reaños and Wölfing, 2017).

CGE models cover direct and indirect price changes, behavioural changes of consumers and producers, and long term general equilibrium effects. This approach considers policy effects on the source side of income in addition to the use side. CGE models assume explicit functional forms of demand and supply functions, and use exogenous parameters for demand elasticities and elasticities of substitution between production sectors (Hassett et al., 2009). Linked models, such as Input-Output and micro-simulations (Creedy and Sleeman, 2006) or CGE models and micro-simulations are further extensions (Labandeira et al., 2009; Vandyck and Van Regemorter, 2014).

\section{A.5 Robustness checks}

This part of the appendix gives a comprehensive overview of the sensitivity analyses and specification tests conducted in this study. First, we address non-independence of observations as a common problem in meta-analysis (Ringquist, 2013). Non-independence of observations generally occurs if at least one country or original study provides multiple 
effects (Ringquist, 2013) which also applies to our analysis (see Appendix Section A.2 and Figure 2). It potentially causes correlated results within countries or studies. Though estimators are not biased or inconsistent they potentially become inefficient (Waldorf and Byun, 2005). We account for that problem by imposing cluster-robust standard errors by country for the subsequent estimations. Additionally, we conduct one regression with cluster-robust standard errors by study to test the impact of the clustering decision.

Second, we conduct several robustness checks on the country modeling. Figure 2 shows five or fewer effects for 32 countries. Countries with few observations have a low time variation and thus pose the risk of multicollinear time-fixed and time-variant variables. For an alternative model specification, we create country groups based on the level of income that replaces the single country dummies. Grouping the countries increases the number of effects per dummy variable but assumes similar fixed-effects for all countries within the respective income group. For another model specification we exclude all timevariant country variables which leaves the respective country dummies to solely account for country differences. Finally we exclude all dummy variables to investigate the overall influence of the time-fixed effects. For all three regression types ("Single Country Dummies", "Group Country Dummies" and "No Country Dummies") we show the results with and without the three time-variant country variables (Figure 3 "Baseline" and "No Country Variables"). In addition we test different combinations of the three time-variant variables.

Third, we test the validity of the ordered probit model specification. For a valid ordered probit specification the regression coefficients of a significantly regressive probit regression ( $1=$ regressive, $0=$ proportional or progressive) should be similar to the ordered probit coefficients. The regression coefficients for a significantly progressive probit regression ( $1=$ progressive, $0=$ proportional or regressive) should be similar in magnitude but opposite in sign (Wehkamp et al., 2018). We conduct the two probit regressions without country dummies because including single country dummies results in infinite iterations.

Fourth, we use a jackknife method to identify the impact of single countries on the results (Gould, 1995). The descriptive analysis shows unequally distributed effects per 
country (see Figure 2) which is a common problem in meta-analyses (Ringquist, 2013). The jackknife method performs $N$ regressions by leaving out the $j$ th observations where $j=1,2, \ldots, N$ is the number of each country $(N=39)$. The method thus provides $N$ coefficients for each moderator variable. Jackknife regression coefficients that largely deviate from the ordered probit coefficient indicate a highly influential country or study.

Finally, we test for multicollinearity using the variance inflation factors and the joint significance of the variable groups using the likelihood-ratio test. The variance inflation factors for model specifications without single country dummies are rather small $(<6.08)$, indicating no problems with multicollinearity. The context variables are the only group of variables that fail the likelihood ratio test $(\mathrm{p}>0.397)$. The other variable groups are at least significant at the $5 \%$ significance level. The pseudo- $R^{2}$ values range from 0.51 for the main regression to 0.13 for the regression without country dummies or variables.

\section{A.6 Regression results overview}

Table V and Table VI show the coefficients of the main regression as well as of the robustness checks without the single country dummy coefficients. 
Table V: Regression results overview - part 1

\section{Single Country Dummies}

\begin{tabular}{|c|c|c|c|c|c|c|}
\hline & Baseline & $\begin{array}{l}\text { Clustering: } \\
\text { Studies }\end{array}$ & $\begin{array}{l}\text { No Country } \\
\text { Variables }\end{array}$ & $\begin{array}{l}\text { Excluding: } \\
\text { Gini and } \\
\text { Poverty Gap }\end{array}$ & $\begin{array}{l}\text { Excluding: } \\
\text { Poverty Gap }\end{array}$ & $\begin{array}{l}\text { Excluding: } \\
\text { Gini }\end{array}$ \\
\hline \multirow[t]{2}{*}{ Subsidy } & 0.211 & 0.211 & 0.788 & 0.864 & -0.316 & 1.235 \\
\hline & $(1.671)$ & $(1.436)$ & $(1.172)$ & (1.173) & $(1.680)$ & $(1.183)$ \\
\hline \multirow[t]{2}{*}{ Transport } & $-1.405^{* *}$ & $-1.405^{* *}$ & $-1.242^{* *}$ & $-1.304^{* *}$ & $-1.446^{* *}$ & $-1.282^{* *}$ \\
\hline & $(0.632)$ & $(0.623)$ & $(0.591)$ & $(0.614)$ & $(0.640)$ & $(0.601)$ \\
\hline \multirow{2}{*}{ Indirect effects } & $-0.628^{* *}$ & $-0.628^{*}$ & $-0.621^{* *}$ & $-0.606^{* *}$ & $-0.631^{* *}$ & $-0.610^{* *}$ \\
\hline & $(0.257)$ & $(0.349)$ & $(0.267)$ & $(0.264)$ & $(0.258)$ & $(0.262)$ \\
\hline \multirow[t]{2}{*}{ Behavioural effects } & $-0.778^{*}$ & -0.778 & $-0.914^{* *}$ & $-0.913^{* *}$ & $-0.792^{*}$ & $-0.868^{* *}$ \\
\hline & $(0.464)$ & $(0.540)$ & $(0.416)$ & $(0.423)$ & $(0.466)$ & $(0.421)$ \\
\hline \multirow[t]{2}{*}{ General equilibrium effects } & 0.028 & 0.028 & -0.462 & -0.311 & -0.121 & -0.079 \\
\hline & $(0.873)$ & $(0.731)$ & $(0.873)$ & $(0.836)$ & $(0.841)$ & $(0.871)$ \\
\hline \multirow[t]{2}{*}{ Lifetime income } & $-1.254^{*}$ & $-1.254^{* *}$ & $-1.224^{*}$ & $-1.245^{*}$ & $-1.271^{*}$ & $-1.233^{*}$ \\
\hline & $(0.693)$ & $(0.569)$ & $(0.677)$ & $(0.684)$ & $(0.702)$ & $(0.677)$ \\
\hline \multirow[t]{2}{*}{ Publication Type } & -0.558 & -0.558 & -0.602 & -0.588 & -0.557 & -0.578 \\
\hline & $(0.650)$ & $(0.340)$ & $(0.600)$ & $(0.631)$ & $(0.648)$ & $(0.646)$ \\
\hline
\end{tabular}




\begin{tabular}{|c|c|c|c|c|c|c|}
\hline Publication Year & $\begin{array}{l}0.069 \\
(0.067)\end{array}$ & $\begin{array}{c}0.069^{* *} \\
(0.035)\end{array}$ & $\begin{array}{l}0.009 \\
(0.028)\end{array}$ & $\begin{array}{l}0.042 \\
(0.058)\end{array}$ & $\begin{array}{l}0.065 \\
(0.069)\end{array}$ & $\begin{array}{l}0.052 \\
(0.057)\end{array}$ \\
\hline GDP per capita & $\begin{array}{l}-0.107 \\
(0.095)\end{array}$ & $\begin{array}{l}-0.107^{*} \\
(0.062)\end{array}$ & & $\begin{array}{l}-0.058 \\
(0.076)\end{array}$ & $\begin{array}{l}-0.096 \\
(0.095)\end{array}$ & $\begin{array}{l}-0.081 \\
(0.079)\end{array}$ \\
\hline Gini & $\begin{array}{l}-0.198 \\
(0.244)\end{array}$ & $\begin{array}{l}-0.198 \\
(0.205)\end{array}$ & & & $\begin{array}{l}-0.242 \\
(0.246)\end{array}$ & \\
\hline Poverty gap & $\begin{array}{l}-0.879^{* * *} \\
(0.272)\end{array}$ & $\begin{array}{l}-0.879^{* * *} \\
(0.241)\end{array}$ & & & & $\begin{array}{l}-1.024^{* * *} \\
(0.261)\end{array}$ \\
\hline Single Country Dummies & yes & yes & yes & yes & yes & yes \\
\hline Cut 1 (or constant) & $\begin{array}{l}124.509 \\
(126.034)\end{array}$ & $\begin{array}{l}124.509^{*} \\
(66.950)\end{array}$ & $\begin{array}{l}15.044 \\
(54.974)\end{array}$ & $\begin{array}{l}78.843 \\
(112.838)\end{array}$ & $\begin{array}{l}115.412 \\
(129.870)\end{array}$ & $\begin{array}{l}98.567 \\
(111.508)\end{array}$ \\
\hline Cut 2 & $\begin{array}{l}124.999 \\
(126.069)\end{array}$ & $\begin{array}{l}124.999^{*} \\
(66.971)\end{array}$ & $\begin{array}{l}15.520 \\
(54.962)\end{array}$ & $\begin{array}{l}79.320 \\
(112.863)\end{array}$ & $\begin{array}{l}115.895 \\
(129.904)\end{array}$ & $\begin{array}{l}99.053 \\
(111.536)\end{array}$ \\
\hline
\end{tabular}

Standard errors in parentheses, Dep. var.: Distributional effect, ${ }^{*} p<0.10,{ }^{* *} p<0.05,{ }^{* * *} p<0.01$ 
Table VI: Regression results overview - part 2

\begin{tabular}{|c|c|c|c|c|c|c|}
\hline & \multicolumn{2}{|c|}{$\begin{array}{c}\text { Group Country } \\
\text { Dummies }\end{array}$} & \multicolumn{4}{|c|}{$\begin{array}{c}\text { No Country } \\
\text { Dummies }\end{array}$} \\
\hline & Baseline & $\begin{array}{l}\text { No Country } \\
\text { Variables }\end{array}$ & Baseline & $\begin{array}{l}\text { No Country } \\
\text { Variables }\end{array}$ & $\begin{array}{l}\text { Probit: } \\
\text { Significantly } \\
\text { Regressive }\end{array}$ & $\begin{array}{l}\text { Probit } \\
\text { Significantly } \\
\text { Progressive }\end{array}$ \\
\hline \multirow[t]{2}{*}{ Subsidy } & 0.151 & 0.082 & -0.183 & $-1.447^{* * *}$ & 0.150 & 0.446 \\
\hline & $(0.651)$ & $(0.622)$ & $(0.373)$ & $(0.383)$ & $(0.389)$ & $(0.393)$ \\
\hline \multirow[t]{2}{*}{ Transport } & $-0.769^{*}$ & $-0.890^{* *}$ & $-0.789^{*}$ & -0.663 & $-0.786^{*}$ & $0.810^{*}$ \\
\hline & $(0.420)$ & $(0.395)$ & $(0.404)$ & $(0.409)$ & $(0.420)$ & $(0.415)$ \\
\hline \multirow[t]{2}{*}{ Indirect effects } & $-0.527^{* *}$ & $-0.565^{* *}$ & $-0.490^{* *}$ & $-0.426^{* *}$ & $-0.467^{* *}$ & $0.519^{* *}$ \\
\hline & $(0.227)$ & $(0.225)$ & $(0.226)$ & $(0.213)$ & $(0.233)$ & $(0.221)$ \\
\hline \multirow[t]{2}{*}{ Behavioural effects } & -0.450 & -0.454 & -0.377 & 0.002 & -0.503 & 0.055 \\
\hline & $(0.357)$ & $(0.345)$ & $(0.349)$ & $(0.399)$ & $(0.348)$ & $(0.458)$ \\
\hline \multirow[t]{2}{*}{ General equilibrium effects } & -0.385 & -0.214 & -0.439 & $-0.883^{*}$ & -0.584 & 0.518 \\
\hline & $(0.692)$ & $(0.656)$ & $(0.635)$ & $(0.467)$ & $(0.661)$ & $(0.916)$ \\
\hline \multirow[t]{2}{*}{ Lifetime income } & $-0.567^{* *}$ & $-0.577^{* *}$ & $-0.582^{* *}$ & $-0.573^{* * *}$ & $-0.686^{* *}$ & $0.521^{*}$ \\
\hline & $(0.271)$ & $(0.255)$ & $(0.264)$ & $(0.190)$ & $(0.297)$ & $(0.284)$ \\
\hline \multirow[t]{2}{*}{ Publication Type } & $-0.607^{* * *}$ & $-0.848^{* * *}$ & $-0.441^{*}$ & $-0.664^{*}$ & $-0.503^{* *}$ & 0.219 \\
\hline & $(0.228)$ & $(0.272)$ & $(0.233)$ & $(0.347)$ & $(0.229)$ & $(0.252)$ \\
\hline \multirow[t]{2}{*}{ Publication Year } & -0.027 & -0.020 & $-0.035^{*}$ & -0.018 & -0.036 & $0.037^{*}$ \\
\hline & $(0.023)$ & $(0.021)$ & $(0.021)$ & $(0.017)$ & $(0.023)$ & $(0.020)$ \\
\hline GDP per capita & $0.024^{* *}$ & & $0.037^{* * *}$ & & $0.040^{* * *}$ & $-0.038^{* * *}$ \\
\hline
\end{tabular}




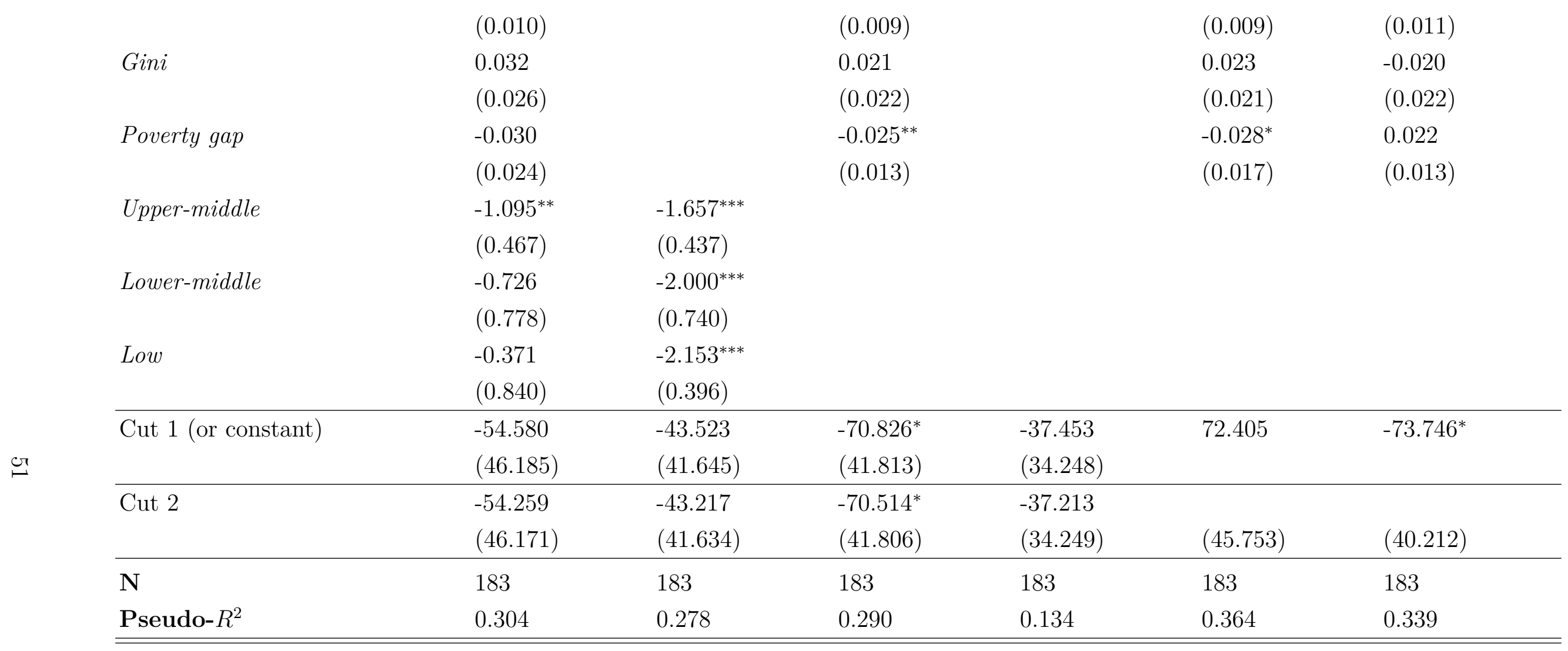

Standard errors in parentheses, Dep. var.: Distributional effect, ${ }^{*} p<0.10,{ }^{* *} p<0.05,{ }^{* * *} p<0.01$ 


\section{A.7 Jackknife findings}

Figure 4: Jackknife country coefficients
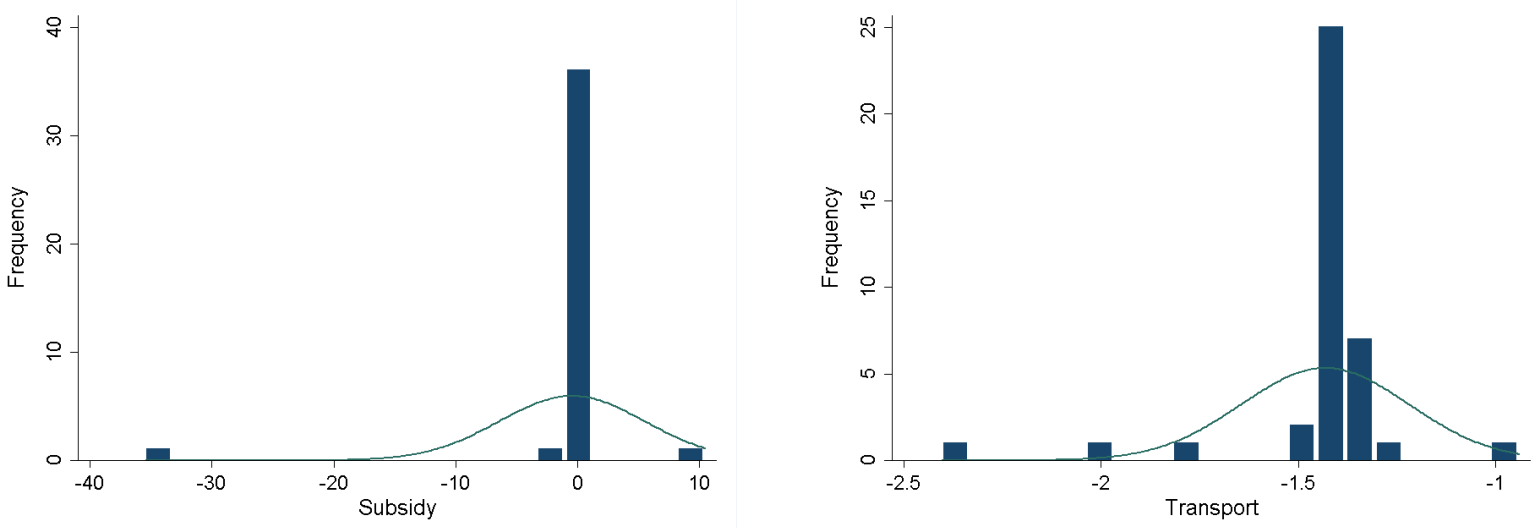

(a) Subsidy

(b) Transport
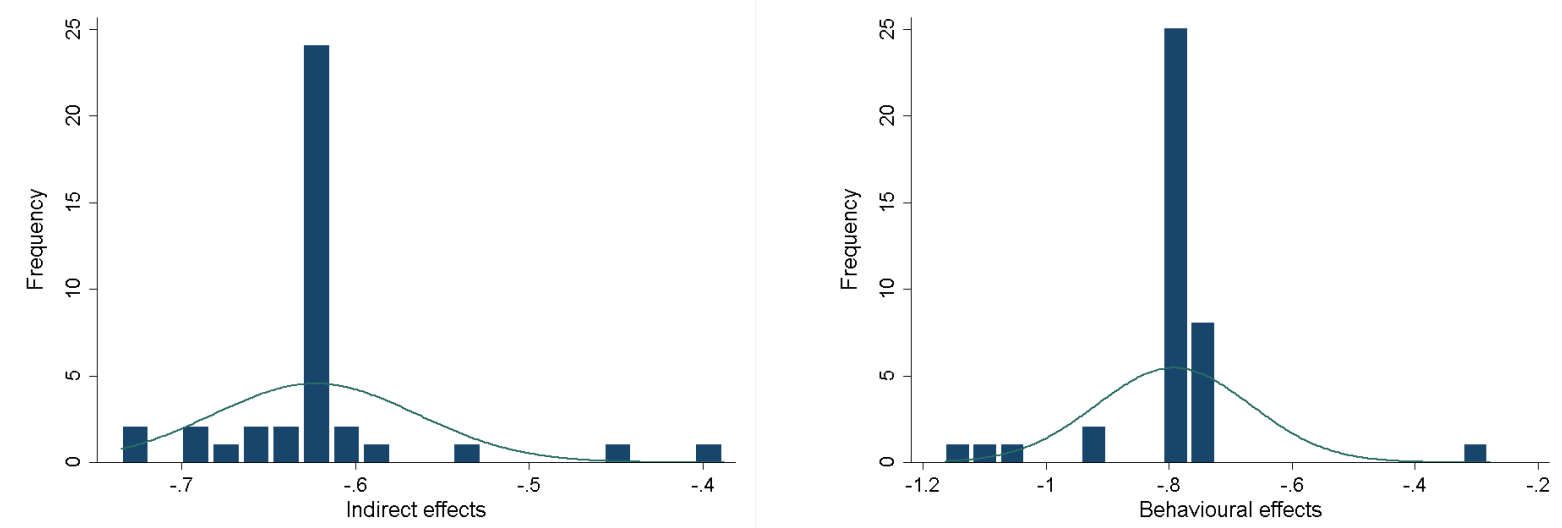

(c) Indirect

(d) Behaviour

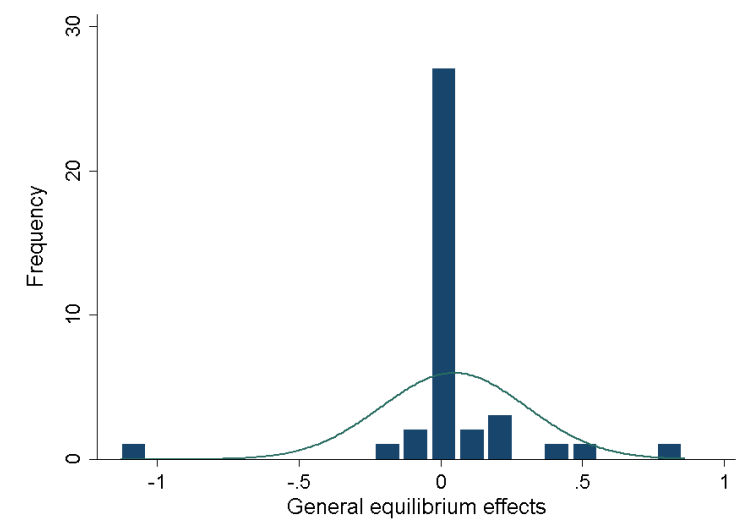

(e) General equilibrium

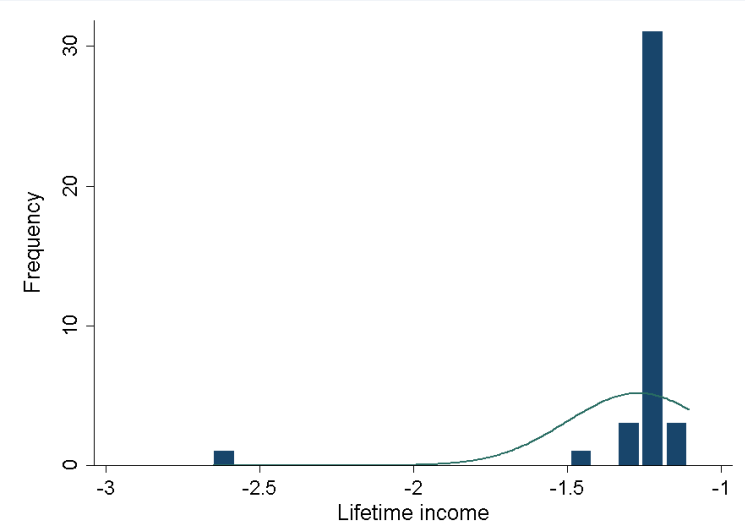

(f) Lifetime income 


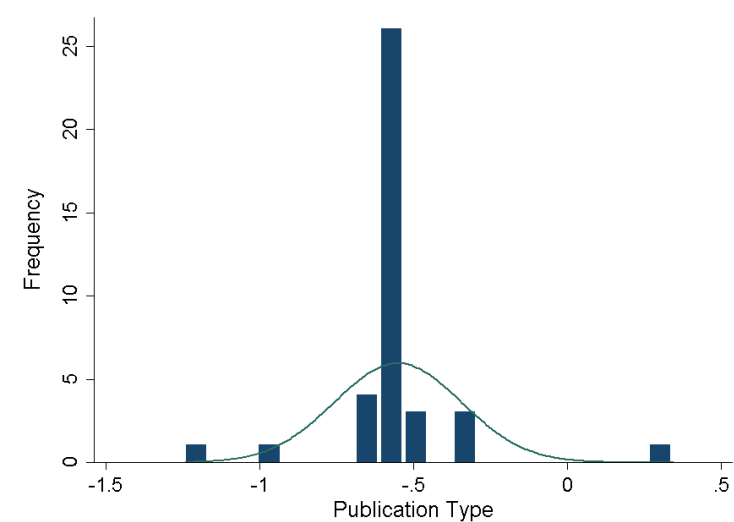

(g) Publication type

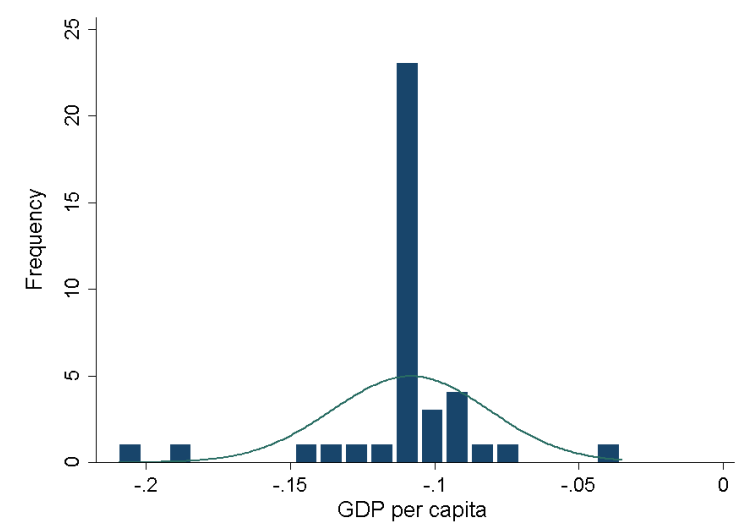

(i) GPD per capita

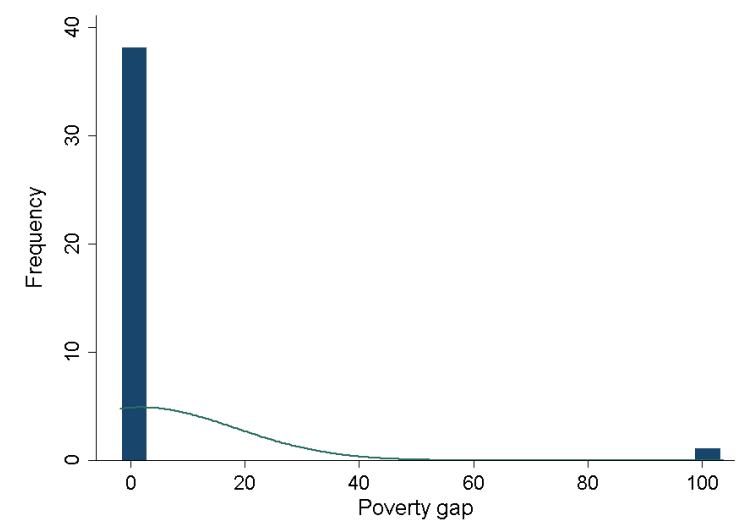

(k) Poverty gap

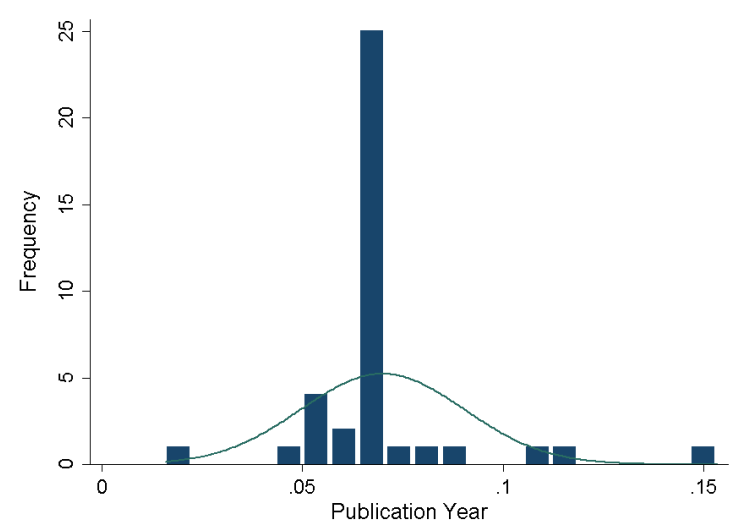

(h) Publication Year

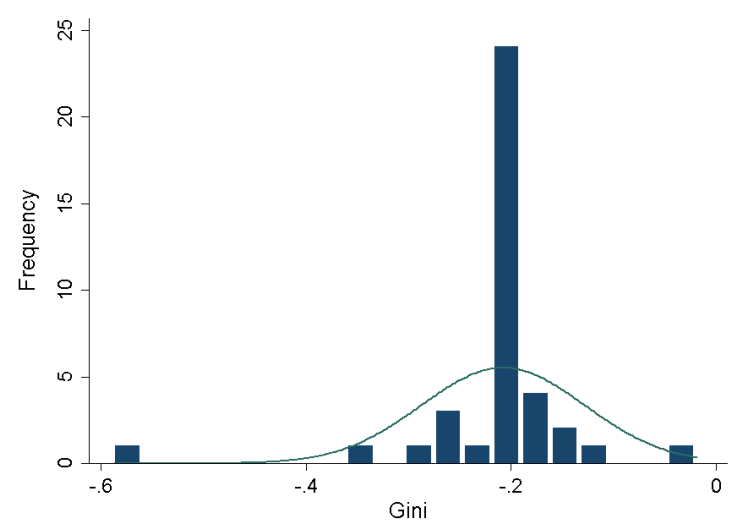

(j) Gini 


\section{A.8 Country dummy coefficients}

Table VII shows the coefficients of the single country dummies for the main regression as well as for the robustness checks.

Table VII: Single country dummy coefficients

\begin{tabular}{|c|c|c|c|c|c|}
\hline Baseline & $\begin{array}{c}\text { Clustering: } \\
\text { Studies }\end{array}$ & $\begin{array}{c}\text { No } \\
\text { Country } \\
\text { Variables }\end{array}$ & $\begin{array}{c}\text { Excluding: } \\
\text { Gini+ } \\
\text { Poverty } \\
\text { Gap }\end{array}$ & $\begin{array}{c}\text { Excluding: } \\
\text { Poverty } \\
\text { Gap }\end{array}$ & $\begin{array}{c}\text { Excluding: } \\
\text { Gini }\end{array}$ \\
\hline
\end{tabular}

\section{Single}

\section{Country}

\section{Dummies}

$\begin{array}{lllllll}\text { Austria } & 0.985 & 0.985 & 1.443 & 1.480 & 0.780 & 1.573 \\ \text { Belgium } & 0.024 & 0.024 & 1.443 & 1.266 & -0.270 & 1.279 \\ \text { Brazil } & 6.468 & 6.468 & -0.550 & -2.953 & 0.760 & 4.417 \\ \text { Canada } & -0.647 & -0.647 & -0.332 & -0.390 & -0.723^{*} & -0.367 \\ \text { Chile } & -4.895 & -4.895 & -6.018^{* * *} & -8.114^{* * *} & -4.985 & -7.265^{* * *} \\ \text { China } & 23.981^{* * *} & 23.981^{* * *} & -0.157 & -2.635 & -2.115 & 27.806^{* * *} \\ \text { Costa Rica } & 3.240 & 3.240 & 0.973 & -1.211 & 0.885 & 1.917 \\ \text { Czech } & -9.808^{* *} & -9.808^{* * *} & -5.560^{* * *} & -7.227^{* * *} & -10.056^{* *} & -7.595^{* * *} \\ \text { Republic } & & & & & \\ \text { Denmark } & -0.228 & -0.228 & 0.337 & 0.803 & -0.723 & 1.078 \\ \text { Estonia } & -1.602 & -1.602 & 0.610 & -1.196 & -2.443 & -0.535 \\ \text { Finland } & -0.700 & -0.700 & 0.610 & 0.543 & -1.039 & 0.602 \\ \text { France } & 1.312 & 1.312 & 2.139^{* *} & 1.843^{*} & 1.229 & 1.812^{*} \\ \text { Germany } & 0.635 & 0.635 & 1.356 & 1.097 & 0.552 & 1.076 \\ \text { Greece } & -1.313 & -1.313 & 0.610 & -0.828 & -0.985 & -1.287 \\ \text { Hungary } & -9.510^{* *} & -9.510^{* * *} & -5.560^{* * *} & -7.623^{* * *} & -9.641^{* *} & -7.967^{* * *} \\ \text { India } & 5.421 & 5.421 & -6.878^{* * *} & -9.736^{* *} & -10.214^{* *} & 8.111 \\ \text { Indonesia } & 14.426^{* *} & 14.426^{* * *} & 1.374 & -1.466 & -2.107 & 17.572^{* * *} \\ \text { Ireland } & 0.673 & 0.673 & 1.028 & 0.860 & 0.593 & 0.890 \\ \text { Italy } & 1.298 & 1.298 & 1.779^{*} & 1.363 & 1.357 & 1.284 \\ \text { Kenya } & 15.314^{* *} & 15.314^{* * *} & -5.509^{* * *} & -8.092^{* *} & -6.094^{*} & 17.190^{* *} \\ \text { Luxembourg } & 12.964^{* *} & 12.964^{* * *} & 6.749^{* * *} & 10.025^{* *} & 12.427^{* *} & 11.269^{* *} \\ \text { Mali } & 27.037^{* *} & 27.037^{* * *} & -6.346^{* * *} & -8.962^{* *} & -7.931^{* *} & 31.910^{* * *} \\ \text { Mexico } & 2.305 & 2.305 & 0.107 & -2.291 & 0.781 & 0.064\end{array}$




\begin{tabular}{lllllll} 
Netherlands & 0.968 & 0.968 & 1.618 & 1.763 & 0.664 & 1.896 \\
New & $5.407^{* * *}$ & $5.407^{* * *}$ & $6.713^{* * *}$ & $6.009^{* * *}$ & $5.538^{* * *}$ & $5.750^{* * *}$ \\
Zealand & & & & & \\
Nigeria & $25.029^{* *}$ & $25.029^{* * *}$ & $-6.966^{* * *}$ & $-9.762^{* *}$ & $-8.081^{*}$ & $29.080^{* * *}$ \\
Pakistan & $31.362^{* * *}$ & $31.362^{* * *}$ & $-1.270^{*}$ & -3.307 & -4.744 & $38.393^{* * *}$ \\
Poland & -4.424 & $-4.424^{* *}$ & -0.614 & -2.554 & -4.246 & -3.181 \\
Serbia & $-10.570^{* *}$ & $-10.570^{* * *}$ & $-5.993^{* * *}$ & $-8.428^{* * *}$ & $-10.868^{* *}$ & $-8.676^{* * *}$ \\
Slovak & $-10.012^{* *}$ & $-10.012^{* * *}$ & $-5.560^{* * *}$ & $-7.380^{* * *}$ & $-10.311^{* *}$ & $-7.715^{* * *}$ \\
Republic & & & & & \\
Slovenia & 2.665 & 2.665 & $6.749^{* * *}$ & $5.372^{* * *}$ & 2.550 & $4.872^{* *}$ \\
South & $13.843^{* *}$ & $13.843^{* *}$ & $-5.501^{* * *}$ & $-7.795^{* *}$ & -2.172 & $11.408^{* *}$ \\
Africa & & & & & & \\
Spain & 0.422 & 0.422 & $1.964^{* *}$ & 1.075 & 0.533 & 0.815 \\
Sweden & -0.250 & -0.250 & 0.344 & 0.721 & -0.688 & 0.949 \\
Switzerland & $9.392^{* * *}$ & $9.392^{* * *}$ & $6.749^{* * *}$ & $8.408^{* * *}$ & $9.007^{* * *}$ & $9.042^{* * *}$ \\
Turkey & -2.688 & -2.688 & -0.930 & -3.120 & -2.585 & -3.193 \\
United & $1.377^{*}$ & 1.377 & $1.743^{* *}$ & $1.359^{*}$ & $1.460^{*}$ & $1.276^{*}$ \\
Kingdom & & & & & & \\
United & $3.257^{*}$ & $3.257^{*}$ & $1.787^{* * *}$ & $1.819^{* * *}$ & $3.513^{*}$ & $1.884^{* * *}$ \\
States & & & & & & \\
\hline \hline
\end{tabular}

Dep. var.: Distributional impact

${ }^{*} p<0.10,{ }^{* *} p<0.05,{ }^{* * *} p<0.01$ 